\title{
Consenso colombiano de expertos sobre recomendaciones basadas en evidencias para el diagnóstico, el tratamiento y el seguimiento de la enfermedad de Fabry con compromiso renal
}

Luis Ramón Barros (DD $\square^{1}$, Sandra Juliana Jiménez (D) 1,2 , Angélica Roncallo (D)1, Francisco López (D)1, Juan Carlos Conde (D)1, Theo Martínez ${ }^{(\mathbb{D} 1 \text {, }}$ John Mauricio Lopera Vargas (DD) 1,3,4, Manuel Garzón ${ }^{(D)}{ }^{1}$, Kelly Rocío Chacón Acevedo (iD) ${ }^{1}$, Juan Politei (D) ${ }^{5}$, Sebastián Jaurretche (iD) 6 , Orlando Olivares (D) ${ }^{7}$, José Gabriel López ${ }^{\mathbb{D}{ }^{8}}$, Gustavo María Ferrari ${ }^{\text {(D) }}{ }^{9}$ y Javier Ibarra ${ }^{10}$

${ }^{1}$ Asociación Colombiana de Nefrología e Hipertensión Arterial, Bogotá, Colombia.

${ }^{2}$ Hospital San Ignacio, Bogotá, Colombia.

${ }^{3}$ Universidad Pontificia Bolivariana, Medellín, Colombia.

${ }^{4}$ Hospital Pablo Tobón Uribe, Medellín, Colombia.

${ }^{5}$ Fundación para el estudio de las enfermedades neurometabólicas, Buenos Aires, Argentina.

${ }^{6}$ Sanatorio Parque de Rosario, Unidad de Trasplante Renal, Pancreático y Cardíaco, Rosario, Santa Fe, Argentina.

${ }^{7}$ Fresenius Medical Care Hospital San José, Bogotá, Colombia.

${ }^{8}$ Clínicas las Vegas, Medellín, Colombia.

${ }^{9}$ Hospital Británico de Buenos Aires, Buenos Aires, Argentina.

${ }^{1}$ OInstituto Mexicano del Seguro Social IMSS, Los Mochis, Sinaloa, México.

Cómo citar: Barros LR, Jiménez SJ, Roncallo A, López F, Conde JC, Martínez T, et al. Consenso colombiano de expertos sobre recomendaciones basadas en evidencias para el diagnóstico, el tratamiento y el seguimiento de la enfermedad de Fabry con compromiso renal. Rev. Colomb. Nefrol. 2022 9(1), e591. https://doi.org/10.22265/acnef.9.1.591

$\checkmark$ Correspondencia: 
Recibido:

$\mathrm{xx} / \mathrm{xxx} / 2022$

Aceptado:

$\mathrm{xx} / \mathrm{xxx} / 2022$

Publicado:

$\mathrm{xx} / \mathrm{xxx} / 2022$

\section{Resumen}

Contexto: la enfermedad de Fabry se comporta como una enfermedad crónica con compromiso multisistémico y alto costo en salud.

Objetivo: generar recomendaciones basadas en la evidencia para el diagnóstico, el tratamiento y el seguimiento de la enfermedad de Fabry con compromiso renal mediante un consenso de expertos.

Métodología: a partir de la búsqueda de evidencia en Pubmed, Embase y Google Scholar entre 2010 y agosto 2020, se formulan recomendaciones sobre la definición, el diagnóstico y el tratamiento de la enfermedad de Fabry en población adulta, las cuales se consultan a un panel de expertos a través de la metodología de consenso Delphi modificado. La calidad de los documentos se evaluó por equipo metodológico aplicando herramientas en función del tipo de documento incluido.

Resultados: se formularon 53 recomendaciones sobre la definición, el diagnóstico y el tratamiento. Un panel de cinco expertos clínicos nacionales e internacionales externos al grupo desarrollador participaron en la consulta preconsenso y 50 recomendaciones fueron acordadas para su inclusión, para tres de ellas se requirió una sesión formal de consenso que se dio en una ronda, incorporando tres nuevas recomendaciones.

Conclusiones: las recomendaciones basadas en evidencia y experticia clínica permitirán orientar de manera estandarizada a nivel nacional y regional, el diagnóstico y el tratamiento de pacientes con sospecha o enfermedad de Fabry con compromiso renal.

Palabras clave: enfermedad de Fabry, diagnóstico, terapia de reemplazo enzimático, glicoesfingolípidos, conferencia de consenso.

\section{Colombian consensus of experts on evidence-based recommendations for diagnosis, treatment and follow-up of fabry's disease with renal involvement}

\section{Abstract}

Background: Fabry disease behaves like a chronic condition, with multisystem involvement and high health care costs.

Objective: To generate evidence-based recommendations for the diagnosis, treatment and follow-up of the Anderson-Fabry disease with renal commitment, through an expert consensus.

Methodology: Based on the search of evidence in PubMed, Embase and Google Scholar between 2010 and August, 2020, recommendations on the definition, diagnosis and treatment of Fabry Disease in adult population were formulated after consulting with an expert panel through the modified Delphi consensus methodology. The quality of the documents was assessed by methodological team applying tools according to the type of document included.

Results: 53 recommendations for the definition, diagnosis and treatment were formulated. A panel of five national and international clinical experts external to the developer group participated in the 
pre-consensus consultation and 50 recommendations were agreed upon for their inclusion. For 3 recommendations, a formal consensus session which took place in one round was required, and 3 new recommendations were incorporated.

Conclusions: The recommendations based on evidence and clinical expertise will allow us to guide the diagnosis and treatment of patients with Fabry disease with renal involvement or suspicion thereof in a standardized manner at national and regional levels.

Keywords: Fabry Disease, Diagnosis, Enzyme Replacement Therapy, Glycosphingolipids, Consensus Conference.

\section{Tabla de Contenidos}

Página

\section{Introducción}

\begin{tabular}{|c|c|}
\hline Alcance y objetivos & 6 \\
\hline Título & 6 \\
\hline 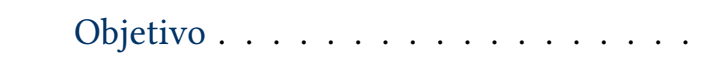 & 6 \\
\hline Población objeto . . . . . . . & 6 \\
\hline Población incluida . . . . . . & 6 \\
\hline Población no incluida . . . . . & 6 \\
\hline Aspectos clínicos . . . . . . . & 7 \\
\hline Usuarios $\ldots \ldots \ldots \ldots$ & 7 \\
\hline$\ldots \ldots \ldots$ & 7 \\
\hline Grupo desarrollador . . . . . . . . & 7 \\
\hline Preguntas clínicas & 7 \\
\hline Búsqueda de la evidencia . & 7 \\
\hline Fuentes de información . . . . . . . & 8 \\
\hline Tamización y selección de la evidencia . & 8 \\
\hline Evaluación de la calidad de la evidencia & 9 \\
\hline Recomendaciones preliminares . . . & 9 \\
\hline Consenso formal de expertos $\ldots \ldots$ & 9 \\
\hline Graduación de recomendaciones & 10 \\
\hline Resultados & 10 \\
\hline Definición y epidemiología & 10 \\
\hline ¿Qué es la enfermedad de Fabry?. & 10 \\
\hline $\begin{array}{c}\text { ¿Cuál es la fisiopatología de la en- } \\
\text { fermedad de Fabry? }\end{array}$ & 11 \\
\hline $\begin{array}{l}\text { termedad de Fabry? .... } \\
¿ C \text { Cuáles son las manifestaciones }\end{array}$ & \\
\hline clínicas generales? . . . . & 11 \\
\hline $\begin{array}{l}\text { ¿Cómo se manifiesta la enferme- } \\
\text { dad a nivel renal? } \ldots \ldots\end{array}$ & 13 \\
\hline $\begin{array}{c}\text { ¿Cuál es el perfil epidemiológico } \\
\text { de la enfermedad de Fabry? }\end{array}$ & \\
\hline
\end{tabular}

Diagnóstico . . . . . . . . . 15

¿Cómo se diagnostica la enfermedad de Fabry? . . . . . . . 15

¿Cómo se diagnóstica el compromiso renal por Fabry? . . 17

¿Cuáles son los exámenes de apoyo para un paciente con enfermedad de Fabry? . .

¿Cuándo indicar la Biopsia renal en paciente con enfermedad de Fabry? . . . . . . . 19

¿Cuáles son los hallazgos histopatológicos en la biopsia renal? . . . . . . . .

¿Cuáles enfermedades glomerulares y tubulares son diagnóstico diferencial de la enfermedad de Fabry? . .

Tratamiento

¿Cómo evaluar la respuesta al tratamiento de terapias de reemplazo enzimático? . .

¿Cuáles son los criterios desde el punto de vista renal para iniciar tratamiento de reemplazo enzimático? . . .

¿Existen otros tratamientos para evitar la progresión renal? 27

¿Cuál es la indicación de chaperonas? . . . . . . . . 28

¿Existe diferencia entre las terapias de reemplazo enzimático en resultados renales? . . . . . . . . . . 
¿Cuál es el impacto clínico de los anticuerpos contra la terapia enzimática? . . . . . 32

¿Cuándo está indicada el cambio de terapia?. . . . . . 34

¿Cuál es el valor del lyso-Gb3 en enfermedad de Fabry? y ¿cuál es la interpretación del lyso-Gb3 en el diagnóstico y seguimiento de enfermedad de Fabry? . . 35

Financiación

Conflicto de interés

Referencias 38

Anexos

Anexo A. Preguntas clínicas desarrolladas 48

Anexo B. Estrategias de búsqueda . . . 50

Anexo C. Evaluación de calidad . . . . . 51

Anexo D. Resultados de la votación de

la consulta preconsenso . . . . . 60

Resultados de la votación de consenso de expertos $($ ronda 1$) \ldots 68$

\section{Índice de tablas}

Grupo desarrollador del consenso . . . 8

Recomendaciones sobre la evaluación inicial y el seguimiento para el paciente con enfermedad de Fabry . 20 


\section{Introducción}

La enfermedad de Fabry, también denominada enfermedad de Anderson-Fabry, es una enfermedad de depósito lisosomal ligada al cromosoma X. Esta condición surge de la deficiencia o ausencia de la enzima lisosomal alfa-galactosidasa A ( $\alpha$-Gal A) que lleva a la acumulación de glicoesfingolípidos en células y tejidos. Esta se comporta como una enfermedad crónica con compromiso multisistémico [1-6].

Tiene una prevalencia estimada de 1 entre 40.000 nacimientos y un caso entre 170.000 hombres [7]. Para el fenotipo clásico se estima una incidencia mundial en la población general de 1 entre 117.000 individuos y específicamente en hombres de un caso entre $40.000[8,9]$ y para el fenotipo de inicio tardío se ha descrito una relación de 7:1 respecto al fenotipo clásico [10].

Los hombres tienen una probabilidad más alta de desarrollar los síntomas de la enfermedad de Fabry y sus manifestaciones son más floridas y severas que en las mujeres. El fenotipo de la enfermedad de Fabry se presenta con dos variedades: una clásica de inicio temprana, caracterizada por dolor neuropático (acroparestesias) en manos y pies, compromiso gastrointestinal, hipohidrosis, angioqueratomas [11] y una variante de inicio tardío en la edad adulta [12] con compromiso principalmente cardiaco, cerebrovascular y renal $[8,13,14]$. La presentación clínica en mujeres puede ser variable, dependiendo del grado de inactivación o expresión del cromosoma $\mathrm{X}$ afectado (fenómeno de Lyon), se pueden presentar síntomas y compromiso severo de órganos blanco, como la enfermedad tipo clásica o síntomas leves [15].

La afectación renal es una causa importante de morbimortalidad, con deterioro progresivo de la función renal hasta llegar a enfermedad renal estadio 5, con necesidad de terapia sustitutiva renal [16], la cual tiene altos costos al sistema de salud. La implementación de programas de tamizaje ha permitido encontrar mayor número de casos en Colombia [17].

La enfermedad de Fabry se define como una enfermedad huérfana por el Estado Colombiano (Congreso de la República) considerando "aquellas crónicamente debilitantes y graves, que amenazan la vida, y con una prevalencia menor de 1 por cada 5.000 personas" [18]. En el Registro Nacional de Pacientes con enfermedades huérfanas se reportan 52.753 casos confirmados en el país [19].

En cuanto a la proporción enfermedades huérfanas en Colombia, desde el 2016 hasta el periodo epidemiológico I del 2021, la enfermedad de Fabry ocupó el puesto 40 y se han notificado 208 casos que corresponden al $0,49 \%$ de los pacientes con enfermedades huérfanas reportadas en el país [17]. 
El manejo de la enfermedad debe estar basado en el diagnóstico oportuno y el tratamiento integral para mejorar la calidad de vida de las personas afectadas. El tratamiento específico de la enfermedad se orienta al uso de la terapia de reemplazo enzimático y de chaperonas farmacológicas, acompañado del tratamiento de soporte. Se realizó una revisión de la enfermedad de Fabry para incorporar los modelos de atención, y se generaron recomendaciones basadas en la evidencia científica disponible que responde a las necesidades del paciente con enfermedad de Fabry y su compromiso renal.

Este consenso colombiano de expertos para el diagnóstico y el tratamiento de enfermedad de Fabry con compromiso renal es una iniciativa de la Asociación Colombiana de Nefrología e Hipertensión Arterial (Asocolnef), liderada por el Comité de Enfermedades Huérfanas para orientar el manejo a nivel nacional y regional de esta enfermedad poco conocida.

\section{Alcance y objetivos}

\section{Título}

Consenso colombiano de expertos sobre recomendaciones basadas en evidencia para el diagnóstico, el tratamiento y el seguimiento de la enfermedad de Fabry con compromiso renal.

\section{Objetivo}

Generar recomendaciones basadas en la evidencia para el diagnóstico, el tratamiento y el seguimiento de la enfermedad de Fabry con compromiso renal mediante un consenso de expertos.

\section{Población objeto}

\section{Población incluida}

Pacientes de 18 años o más con diagnóstico o sospecha de enfermedad de Fabry y compromiso renal.

\section{Población no incluida}

El documento no incluye población pediátrica, ni mujeres embarazadas. 


\section{Aspectos clínicos}

En el consenso se incluyen recomendaciones acerca del diagnóstico, el tratamiento y el seguimiento de la enfermedad de Fabry con compromiso renal.

\section{Usuarios}

Los usuarios directos de las recomendaciones basadas en evidencia aprobadas por el colectivo experto incluyen médicos generales, especialistas y demás profesionales de la salud involucrados en la atención de pacientes con la enfermedad de Fabry y compromiso renal.

\section{Metodología}

Al tener en cuenta la necesidad de generar recomendaciones basadas en la evidencia que orienten la práctica clínica con respecto al diagnóstico, el tratamiento y el seguimiento de la enfermedad de Fabry con compromiso renal, las preguntas de interés del grupo desarrollador se abordaron mediante la revisión de literatura y el consenso de expertos.

\section{Grupo desarrollador}

El grupo desarrollador estuvo conformado por expertos clínicos especialistas en Nefrología con experiencia en el manejo de pacientes con enfermedad de Fabry, variante renal. Asimismo, se contó con epidemiólogos clínicos expertos en búsqueda sistemática de la literatura, calificación de la calidad de evidencia y desarrollo del consenso de expertos. En la Tabla 1 se presenta cada integrante del grupo desarrollador, su perfil profesional y su rol en el desarrollo de la guía.

\section{Preguntas clínicas}

El grupo desarrollador definió las preguntas de interés y se categorizaron en función del aspecto clínico abordado en el diagnóstico y el tratamiento. Las preguntas formuladas se presentan en el anexo A.

\section{Búsqueda de la evidencia}

La búsqueda de la evidencia se realizó a través de una revisión sistemática de la literatura. Las consultas en función de la fuente se detallan a continuación. 
Tabla 1. Grupo desarrollador del consenso

\begin{tabular}{|c|c|c|}
\hline Nombre & Perfil profesional & $\begin{array}{c}\text { Rol en el desarrollo de } \\
\text { la guía }\end{array}$ \\
\hline Luis Ramón Barros & MD, Esp. en Nefrología. & Líder clínico \\
\hline Sandra Juliana Jiménez & MD, Esp. en Nefrología. & Experto clínico \\
\hline Angélica Roncallo & MD, Esp. en Nefrología. & Experto clínico \\
\hline Juan Carlos Conde & MD, Esp. en Nefrología. & Experto clínico \\
\hline Francisco López & MD, Esp. en Nefrología. & Experto clínico \\
\hline Manuel Garzón & MD, Esp. en Nefrología. & Experto clínico \\
\hline Mauricio Lopera & MD, Esp. en Nefrología. & Experto clínico \\
\hline Theo Martínez & MD, Esp. en Nefrología. & Experto clínico \\
\hline Kelly Chacón Acevedo & $\begin{array}{c}\text { Ft, MSc Epidemiología } \\
\text { Clínica }\end{array}$ & Líder metodológico \\
\hline
\end{tabular}

\section{Fuentes de información}

Para la identificación de evidencia a través de bases de datos electrónicas se realizó una búsqueda sistemática en Medline vía Pubmed y Embase, también en organismos desarrolladores y compiladores de GPC, Google y Google Scholar y se consultó a los expertos clínicos sobre bibliografía que no haya sido encontrada en el proceso de búsqueda.

La estrategia de búsqueda fue diseñada mediante la combinación de vocabulario controlado, términos libres y operadores booleanos. Las estrategias de búsqueda se encuentran en el anexo B.

\section{Tamización y selección de la evidencia}

Se realizó la tamización por título y resumen de la información de manera independiente por dos revisores: experto clínico y metodólogo, en búsqueda de evidencia, orientada específicamente al diagnóstico o el tratamiento de la enfermedad de Fabry. En caso de desacuerdos estos se resolvieron mediante consenso entre los revisores.

Los documentos preseleccionados en la tamización fueron revisados a texto completo y acordados en consenso por los integrantes del equipo clínico y metodológico. Los documentos fueron incluidos si cumplían los siguientes criterios:

- Población o condición: pacientes adultos (18 años o más) con diagnóstico o sospecha de enfermedad de Fabry con compromiso renal. 
- Aspecto clínico abordado: diagnóstico y tratamiento.

- Publicación entre enero 2010 y agosto 2020.

- No hubo restricción por tipo de documento.

\section{Evaluación de la calidad de la evidencia}

Para los documentos incluidos que cumplieron los criterios definidos previamente, se realizó la calificación de la calidad de la evidencia considerando herramientas válidas por cada tipo de estudio, tales como AGREE II para GPC, AMSTAR-2 para RSL, herramienta de riesgo de sesgo de Cochrane (RoB) para ensayos clínicos y herramientas Joanna Briggs Institute para los demás tipos de estudio.

\section{Recomendaciones preliminares}

A partir de la información recolectada, se realizó una síntesis narrativa por cada pregunta y se plantearon las recomendaciones preliminares, considerando la posibilidad de implementación de las sugerencias en el país.

\section{Consenso formal de expertos}

A través de la metodología Delphi modificada, se llevó a cabo el consenso de expertos. Todos los participantes declararon si tenían algún conflicto de interés. El grupo de gestión de conocimiento de Asocolnef analizó el conflicto declarado y su potencial efecto en las respuestas emitidas para garantizar la transparencia del consenso.

Se definió un acuerdo cuando la recomendación alcanzó una votación de al menos el $80 \%$ a favor, considerando como denominador para cada recomendación el número total de participantes en la votación de esa recomendación.

Inicialmente se realizó una consulta preconsenso para identificar las recomendaciones que requerían sesión de consenso virtual. Esta consulta se realizó entre el 28 de junio y el 19 de julio del 2021 y contó con la participación de cinco expertos clínicos diferentes al grupo desarrollador. Fue necesaria una sesión virtual de consenso que se realizó el día 03 de agosto del 2021 a través de la plataforma Zoom. Se presentaron las recomendaciones no aprobadas en la consulta preconsenso y las nuevas recomendaciones, considerando las observaciones de los expertos consignadas en la consulta inicial, se dio lugar a la discusión y se realizó la votación, fue necesaria una ronda de discusión por recomendación hasta lograr el acuerdo. 


\section{Graduación de recomendaciones}

El grupo desarrollador clasificó las recomendaciones según la dirección y la fuerza, dando lugar a recomendaciones a Favor o en Contra y Fuertes o Débiles, considerando la calidad de evidencia, balance de riesgos beneficios, consumo de recursos o disponibilidad en el contexto local [20] y las observaciones emitidas por el colectivo experto.

\section{Resultados}

Se encontraron 1427 documentos y eliminaron 142 duplicados, por lo cual se revisaron a título y resumen 1285 documentos y 414 fueron revisados a texto completo. Finalmente, se seleccionaron 81 documentos que respondían las preguntas formuladas por el grupo desarrollador. La calidad de los documentos fue entre baja y moderada, y los resultados se detallan en el anexo C.

\section{Definición y epidemiología}

\section{¿Qué es la enfermedad de Fabry?}

La enfermedad de Fabry es una enfermedad huérfana, hereditaria, progresiva, crónica y con compromiso multisistémico, de morbilidad significativa y mortalidad prematura [5,21-26].

Esta condición se clasifica dentro del grupo de las enfermedades de depósito lisosomal y ocupa el segundo lugar dentro de este [11]. Se caracteriza por la acumulación de globotriaosilceramida (GB-3), globotriaosilesfingosina (liso-Gb3) y galabiosilceramida, a causa de la mutación del gen GLA en el cromosoma X, el cual afecta la presencia o la actividad de la enzima hidrolasa $\alpha$-Gal A, encargada de la degradación de los glucoesfingolípidos [27-30]. Al ser una condición asociada al cromosoma $\mathrm{X}$ de patrón recesivo, esta afecta predominantemente a los hombres hemicigotos, sin embargo, las mujeres también pueden presentar la enfermedad tipo clásica o leves síntomas leves (fenómeno de Lyon), dependiendo del grado de inactivación o expresión del cromosoma X afectado. Se ha descrito que cerca del $70 \%$ de las mujeres manifiestan la enfermedad [31], aunque de manera tardía y característicamente menos severa [12,27,32].

\section{Recomendaciones}

- La enfermedad de Fabry es una condición de compromiso multisistémico, huérfana, hereditaria y ligada al cromosoma X que pertenece al grupo de las enfermedades de depósito lisosomal.

\section{Sin gradar}




\section{¿Cuál es la fisiopatología de la enfermedad de Fabry?}

La enfermedad de Fabry consiste en la acumulación anormal de glicoesfingolípidos del tipo GB-3 y Lyso-Gb3, por la deficiencia absoluta o parcial de la enzima hidrolasa alfa-galactosidasa A, en lisosomas de diferentes células (endotelio, podocitos, cardiomiocitos, etc.), tejidos y líquidos corporales, de manera que ocasiona disfunción celular, remodelación tisular, fibrosis e isquemia que lleva a daño severo de órganos diana como riñón, corazón y sistema nervioso central y periférico. También pueden verse afectados otros tejidos como piel y cornea [1-6].

A pesar de que el mecanismo fisiopatológico de la enfermedad de Fabry no está claramente definido, el mecanismo más probable es que la interacción de la Gl3 y lyso-Gb3 con receptores como los Toll-like desencadenan respuestas inflamatorias por estímulo del factor nuclear kappa beta y respuestas fibróticas a través de la síntesis del factor transformante beta que ocasiona la transición desde estirpe epitelial a mesenquimal, lo que a su vez genera una expresión de moléculas profibróticas. Por otra parte, el compromiso de las células capilares puede generar obstrucción microvascular e isquemia crónica [33-35]. La fibrosis tisular que es multifactorial, es mediada entre otras por el compromiso del metabolismo energético, la lesión de pequeños vasos, la disfunción de canales iónicos en células endoteliales, el aumento del estrés oxidativo y las alteraciones en la autofagia y la isquemia [23, 29, 36].

En el riñón, la acumulación de Gb-3 ocurre principalmente en las células endoteliales de los capilares glomerulares, capilares peritubulares, endotelio vascular, podocitos, células del músculo liso y células del epitelio tubular [37,38]. Como ya se mencionó, esta acumulación probablemente estimula la liberación de factores inflamatorios y profibróticos que llevan a lesión podocitaria con la consiguiente esclerosis glomerular [39].

Las lesiones descritas empeoran a lo largo de la evolución de la enfermedad y llevan a estadios de insuficiencia renal crónica moderada a severa entre la tercera y la quinta década de vida [40-42]. Se ha evidenciado que los cambios estructurales del riñón en biopsia ocurren antes de las manifestaciones clínicas renales [43].

\section{¿Cuáles son las manifestaciones clínicas generales?}

El fenotipo de la enfermedad de Fabry depende del tipo de mutación, sexo (grado de inactivación aleatoria de cromosoma X afectado) y modificadores genéticos aún desconocidos [44], a pesar de esto, se han descrito claramente dos fenotipos a saber, uno clásico temprano y severo y uno tardío o no clásico [45]. 
El fenotipo clásico comienza con manifestaciones clínicas a temprana edad [13], generalmente después de los tres años. Los hombres hemicigotos generalmente tienen presentaciones más graves con respecto a las mujeres [22,46]. Dentro de las manifestaciones clínicas tempranas de este fenotipo, se encuentran la acroparestesia, ("crisis de Fabry" dadas por dolor intenso, episódico, tipo ardor en manos y pies), la intolerancia al ejercicio por hipo $\mathrm{o}$ anhidrosis, fiebre, trastornos gastrointestinales, angioqueratoma, catarata subcapsular y cornea verticillata $[8,11,35,36,47]$. El tinnitus, la hipoacusia y el vértigo también son signos de enfermedad de Fabry [12].

En un análisis de síntomas de 108 pacientes con enfermedad de Fabry provenientes de 51 familias francesas, el 37,9\% eran hombres con edad promedio de diagnóstico de 25,9 años (de: 14,2 años), mientras que para las mujeres la edad promedio de diagnóstico fue 37,5 años (de: 16,3 años).

Los cinco síntomas más frecuentes fueron acroparestesias $(66,7 \%)$, cornea verticillata $(53,7 \%)$, dishidrosis (47,2\%), angioqueratoma (44,4\%) y enfermedad cardiaca (38,9\%). En este análisis, se encontró que la edad mayor a 25 años en hombres y 35 años en mujeres son puntos de corte para predecir la afectación de órganos a causa de la enfermedad de Fabry, de manera que el riesgo de enfermedad cardiaca fue de 10 veces (IC 95\% 3,0-33,7) y de enfermedad renal fue de 2,7 veces (IC $95 \%$ 1,3-10,3) en esta población respecto a las otras edades [47].

Para las mujeres, los eventos cardiovasculares ocurren en una mediana de edad de 43 años, mientras que los eventos cerebrovasculares suceden en una mediana de 47 años. Para los hombres estos eventos ocurren en medianas de 38 años y 41 años, respectivamente [48].

Por otra parte, el fenotipo tardío se presenta en la edad adulta, después de los 30 años [12] con afectación principalmente cardiaca, la cual puede asociarse con compromiso cerebrovascular y renal $[8,13]$ en ausencia de manifestaciones clínicas tempranas descritas en fenotipo clásico [49]. Las manifestaciones clínicas están dadas por el grado de cardiopatía hipertrófica, fibrosis y anormalidades en el sistema de conducción cardiaco [21,35,36,39].

\section{Recomendaciones}

- Las manifestaciones clínicas de la enfermedad de Fabry se asocian con el fenotipo que puede ser clásico (inicio temprano) o tardío. El fenotipo clásico se caracteriza por mostrar temprano signos y síntomas que incluyen acroparestesia, hipo o anhidrosis, trastornos gastrointestinales, intolerancia al ejercicio, fiebre, angioqueratoma, dolor neuropático, cornea verticillata, tinnitus y vértigo, entre otros. Durante la historia natural de la enfer- 
medad, los pacientes evolucionan a daño renal, cardiaco y cerebrovascular.

\section{Fuerte a favor}

- El fenotipo tardío se presenta en la adultez con predominio de afección cardiaca, y grados variables de compromiso renal y cerebrovascular.

\section{Fuerte a favor}

- La edad de inicio de manifestaciones de la enfermedad en el fenotipo clásico ocurre en la niñez, a partir de los 3 años, y para el fenotipo tardío después de los 30 años.

\section{Fuerte a favor}

\section{¿Cómo se manifiesta la enfermedad a nivel renal?}

El compromiso renal en la mayoría de ocasiones es el primer signo de daño grave de afectación de órganos blanco a causa de la enfermedad de Fabry clásica [36]. Clínicamente, la enfermedad renal secundaria a Fabry se manifiesta por el desarrollo progresivo de proteinuria de intensidad creciente y por una disminución gradual de la función renal [30,39,43,50,51].

La proteinuria puede estar presente desde la infancia, incluso desde los 6 años, y asociarse con desarrollo de enfermedad renal crónica severa en la adultez $[8,11,12]$. La proteinuria se ha definido como un factor de riesgo independiente que acelera el deterioro renal y compromete el grado de respuesta a la terapia de remplazo enzimático [52].

Tempranamente, el daño renal puede manifestarse por hiperfiltración con o sin albuminuria. En el $10 \%$ de los hombres y el $30 \%$ de las mujeres con ERC estadio 3, el daño renal cursa sin proteinuria, sin embargo, al progresar el daño, la albuminuria se hace presente y se acompaña de disminución en la tasa de filtración glomerular (TFG) [8]. También pueden presentarse de manera temprana poliuria y nicturia como resultado de alteración de los mecanismos de concentración urinaria [53].

La progresión del daño renal es más común en hombres, se ha sugerido que al menos la mitad de los que tienen fenotipo clásico desarrollan lesión renal antes de los 35 años, mientras que el $100 \%$ la desarrollan después de los 50 años $[8,36]$. En las mujeres, el daño renal se manifiesta a una mediana de edad de 38 años [48]. En el análisis reportado por Kaminsky et al. en 2013, en una cohorte de pacientes franceses con Fabry se encontró que la edad era: mayores de 25 años en hombres y de 35 años en mujeres, y aumentaba el riesgo de desarrollar enfermedad renal (RR: 2,7, IC $95 \%$ 1,3-10,3) respecto a las otras edades [47]. 
Se ha descrito que la aparición de múltiples quistes parapiélicos puede ser una característica que alerte a los médicos de la presencia de la enfermedad de Fabry en pacientes con enfermedad renal de causa no clara, ya que estos son más frecuentes que en la población general (28\% vs. $1 \%)$, en función de la edad [54].

\section{Recomendaciones}

- Las manifestaciones renales de la enfermedad de Fabry se caracterizan por hiperfiltración con o sin albuminuria, progresión a proteinuria manifiesta y disminución progresiva de la TFG. Puede observarse también nicturia como consecuencia de alteraciones en capacidad de concentración urinaria.

\section{Fuerte a favor}

- El compromiso renal en Fabry clásico se presenta antes de los 25 años en hombres y 35 años en mujeres y en variantes tardías puede aparecer después de estas edades.

\section{Fuerte a favor}

\section{¿Cuál es el perfil epidemiológico de la enfermedad de Fabry?}

La enfermedad de Fabry es una enfermedad huérfana del grupo de las enfermedades lisosomales, con una prevalencia estimada de 1 entre 40.000 nacimientos y un caso entre 170.000 hombres [7]. Para el fenotipo clásico se estima una incidencia mundial en la población general de 1 entre 117.000 individuos y, específicamente en hombres, de 1 caso entre 40.000 [8,9]. Más recientemente se ha estimado una frecuencia de Fabry clásico de 1 en 22.570 hombres y de variante tardía de 1 entre 1390 hombres [13]. Asimismo, una prevalencia de 1 caso entre 3000 individuos, según el portal de enfermedades raras y medicamentos huérfanos [55].

En el estudio de Turkmen et al. [56] de 2016, llevado a cabo con el objetivo de estimar la prevalencia de enfermedad de Fabry en pacientes con ERC sin terapia de soporte renal en Turquía, se encontró una prevalencia del 0,9\% en población masculina. De la misma manera, en el estudio de Yeniçerioğlu et al. de 2017, en población con ERC sin diálisis se reportó una prevalencia del $0,2 \%$ [33].

Debido a la aparición de complicaciones tardías de la enfermedad de Fabry, los pacientes tienen una reducción en la supervivencia en comparación con la población general. El promedio de edad al morir es de 55 años en pacientes hemicigotos y las complicaciones cardiovasculares son causantes, en mayor frecuencia, de la mortalidad prematura en esta población [8]. Para las mujeres, la expectativa de vida es de 70 años [12]. 
A pesar de que la población pediátrica no es el alcance de este documento, es importante mencionar que con las estrategias de tamización masiva, las cifras pueden ser diferentes, en un reporte italiano posterior a la tamización neonatal se reportó una prevalencia de 1 entre 3100 nacidos [10] y en la población de Taiwán fue 1 caso entre 1500 hombres recién nacidos [16]; sin embargo, se debe tener precaución en la interpretación de los datos, porque muchas de las mutaciones encontradas podrían no asociarse con el desarrollo de la enfermedad y ser variantes de significado incierto o no necesariamente patológicas [57].

En Colombia, la enfermedad de Fabry ocupó el puesto 40 entre las enfermedades huérfanas, con 208 casos según Sivigila para el periodo correspondiente entre 2016 a I-2021. Vale la pena resaltar que esta cifra está subestimada, teniendo en cuenta que el registro corresponde únicamente a pacientes que reciben tratamiento para la enfermedad de Fabry [17].

\section{Recomendaciones}

- La enfermedad de Fabry es una enfermedad de baja frecuencia y no se conoce hasta ahora información exacta de la prevalencia de la enfermedad en Colombia, por lo que estudios que permitan establecerla son necesarios.

\section{Fuerte a favor}

\section{Diagnóstico}

\section{¿Cómo se diagnostica la enfermedad de Fabry?}

Dada la variabilidad de las manifestaciones clínicas, la baja frecuencia de la enfermedad y, por tanto, al poco conocimiento médico sobre la misma, el diagnóstico de la enfermedad de Fabry puede retrasarse hasta 10 o más años, después de la aparición de los síntomas $[48,58]$.

Para el diagnóstico de la enfermedad de Fabry se han descrito: la evaluación clínica completa que incluye criterios clínicos, bioquímicos, moleculares y patológicos como la presencia de córnea verticillata o angioqueratomas; la medición de la actividad de la enzima GLA en plasma o leucocitos menor al $5 \%$, biomarcadores en plasma u orina elevados (lysoGB3); cambios moleculares atribuidos a mutación genética y hallazgos característicos en biopsias de tejidos afectados por la enfermedad (riñón, corazón, piel, etc.) [59]; así como el antecedente familiar de la enfermedad de Fabry $[9,11,35,60]$. Al respecto, la guía canadiense del 2019 recomendó diagnosticar la enfermedad de Fabry ante la presencia de tres de los cuatro criterios descritos anteriormente. 
La actividad de la GLA puede ser medida en plasma, leucocitos, cultivos celulares o gota de sangre seca [49], sin embargo, la medición en leucocitos es reconocida como el estándar de oro, además de su medición en simultáneo con otra enzima lisosomal [61]. La medición de la actividad de la enzima GLA es sugerida como la prueba diagnóstica en hombres [9], los resultados de deficiencia completa o actividad insignificante $<5 \%$ de la media normal son indicativos de enfermedad de Fabry [48,61,62]; sin embargo, la prueba genética permite esclarecer en esta población el fenotipo de la enfermedad, orientar el manejo y prevenir complicaciones.

La medición de actividad de la GLA no es útil en población femenina debido a que puede estar en rango normal en alrededor del $40 \%$ de los casos, por lo que el diagnóstico confirmatorio recomendado de enfermedad de Fabry en mujeres se realiza con la identificación de la mutación de GLA (estudio molecular), además de ser útil en estudios familiares $[9,11,53,61,62]$.

La presentación de dolor neuropático, angioqueratomas o córnea verticillata respaldan el diagnóstico en individuos sospechosos de Fabry sin manifestaciones renales, cardiacas o cerebrales. En el caso de la córnea verticillata se ha sugerido excluir la relación con uso de medicamentos como cloroquina y amiodarona, entre otros [62]. Otras manifestaciones clínicas diagnósticas, como ya se mencionó, incluyen acroparestesias y, más tardíamente, hipertrofia ventricular izquierda [53].

Al tener en cuenta el fenotipo tardío de la enfermedad, las guías de la Asociación Renal Europea y Asociación de Diálisis y Trasplante Europea sugieren la tamización de Fabry en menores de 50 años sin diagnóstico claro de enfermedad renal, aunque en mujeres la tamización puede ser a mayor edad [9].

\section{Recomendaciones}

- Se recomienda realizar una evaluación integral del paciente con sospecha de enfermedad de Fabry clásico (córnea verticillata, acroparestesias y dolor neuropático), revisión retrospectiva de sistemas y realizar tempranamente pruebas diagnósticas.

\section{Fuerte a favor}

- Se recomienda considerar los criterios clínicos, bioquímicos, moleculares e histopatológicos para el diagnóstico de la enfermedad de Fabry.

\section{Fuerte a favor}


- En el paciente con alteración renal y sospecha de enfermedad de Fabry se sugiere considerar la biopsia renal como una prueba diagnóstica complementaria.

\section{Débil a favor}

- Se recomienda realizar un diagnóstico genético de la enfermedad de Fabry en mujeres, a partir de la identificación de la mutación de gen GLA.

\section{Fuerte a favor}

- Se recomienda evaluar la actividad de la enzima GLA para el diagnóstico de enfermedad de Fabry en hombres y de manera complementaria realizar estudio genético en busca de mutación de gen GLA.

\section{Fuerte a favor}

\section{¿Cómo se diagnóstica el compromiso renal por Fabry?}

Dadas las manifestaciones renales y la edad de presentación en pacientes con enfermedad de Fabry descritas previamente, la medición de albuminuria es una alternativa diagnóstica sugerida por diferentes autores $[9,23,36,48,63]$. Se ha sugerido que la función renal se clasifique por estadios de la TFG y por categorías de albuminuria, según las guías Kidney Disease: Improving Global Outcomes 2012 (KDIGO 2012) y que su estimación se realice con la fórmula CKD-EPI en adultos y la fórmula modificada de Schwartz en niños para la estimación de la TFG [8,36]. También se ha sugerido el uso del cociente albúmina/creatinina en orina para estimar la excreción urinaria de proteínas en 24 horas [23,33].

La podocituria se ha descrito como un biomarcador de aparición temprana en la lesión renal, previo a la aparición de albuminuria, asimismo podría sugerir la necesidad de tratamiento, sin embargo, esta técnica no está estandarizada y existen barreras de disponibilidad de medición en el contexto colombiano [8,62, 64, 65].

\section{Recomendaciones}

- Se recomienda usar la definición y clasificación de ERC propuesta por KDIGO para describir la afectación renal por enfermedad de Fabry.

\section{Fuerte a favor}

- Se recomienda realizar medición de TFG, cociente albuminuria/creatinuria y proteinuria de 24 horas como marcadores de compromiso y progresión renal por enfermedad de Fabry.

\section{Fuerte a favor}


- Se sugiere realizar ecografía renal para evaluación estructural inicial.

\section{Opinión de expertos}

- Se considera que en el futuro la podocituria podría ser una herramienta de valor para definir el compromiso renal temprano, por lo que debe definirse el marcador de podocitos a usar, ya que en la enfermedad de Fabry altera la expresión de podocalixina en relación con la de sinaptopodina.

\section{Opinión de expertos}

\section{¿Cuáles son los exámenes de apoyo para un paciente con enfermedad de}

\section{Fabry?}

Las ayudas diagnósticas pueden ser de tres tipos: de laboratorio, imagenológicas y escalas de evaluación específicas, todas de gran importancia para valorar la afectación multiorgánica que se presenta en los pacientes con enfermedad de Fabry.

En general, los consensos sugieren examen físico completo con toma de signos vitales y evaluación detallada de cada sistema; valoración objetiva del dolor, aplicando escalas cuantitativas del compromiso neuropático, del compromiso gastrointestinal y de la calidad de vida; evaluación de la función renal con mediciones de albuminuria y proteinuria en orina de 24 horas y estimación de la tasa de filtración glomerular (TFG); laboratorios clínicos completos que incluyan cuadro hemático, química sanguínea y electrólitos; electrocardiograma, ecocardiograma transtorácico modo M, 2D y Doppler y resonancia nuclear magnética cardiaca. Asimismo, se propone la realización de audiometría, resonancia nuclear magnética cerebral y examen de la córnea con lámpara de hendidura. Otras alternativas, dependientes de disponibilidad, incluyen la biopsia de piel, test de cuantificación sensitiva (Quantitative Sensory Testing o QST) y tiempo de vaciamiento gástrico [8].

La guía de Mejor Práctica Renal Europea (ERBP por siglas en inglés) ha recomendado la tamización de hombres con ERC en ausencia de un diagnóstico renal fiable, mientras que para las mujeres se propone realizarla en casos de ERC no explicada con síntomas sugestivos de enfermedad de Fabry y se ha desaconsejado su realización en la población general [9].

Con respecto al seguimiento de daño de órgano blanco, la guía ha sugerido la conformación de equipos multidisciplinarios con, al menos, cardiología, neurología y nefrología.

\section{Recomendaciones}

- Se recomienda realizar una evaluación clínica integral al menos una vez al año en pacientes con sospecha de enfermedad de Fabry, incluyendo examen físico, evaluación de 
dolor neuropático, de compromiso gastrointestinal y de calidad de vida.

\section{Débil a favor}

- Se sugiere realizar una tamización de enfermedad de Fabry en pacientes con alteración en la función renal sin causa conocida.

\section{Fuerte a favor}

- Se recomienda realizar medición de albuminuria y proteinuria, TFG, laboratorios clínicos completos, electrocardiograma y ecocardiograma en adultos con sospecha de enfermedad de Fabry, al menos una vez al año para evaluar el compromiso de órganos (tabla 2).

Débil a favor

- Se recomienda que la evaluación sea integral y multidisciplinaria, incluyendo especialistas en cardiología, neurología y nefrología.

\section{Fuerte a favor}

\section{¿Cuándo indicar la Biopsia renal en paciente con enfermedad de Fabry?}

Dada la utilidad que tiene la biopsia renal en la identificación del compromiso renal causado por la enfermedad de Fabry, algunos autores la han considerado importante en el diagnóstico y seguimiento de la enfermedad [11,12,52,53, 62].

La biopsia renal permite cuantificar el porcentaje de glomeruloesclerosis, de daño tubulointersticial, el grado de acumulación de Gb-3, entre otros, previo deterioro de la función renal o como alternativa para la toma de decisión de comienzo de terapia de reemplazo enzimático (TRE); sin embargo, algunos expertos han limitado su uso a condiciones específicas, como descartar otro tipo de patología concomitante en casos estables de enfermedad de Fabry que presentan deterioro súbito o rápidamente progresivo de la función renal; incremento súbito de la albuminuria, albuminuria categoría A3 o proteinuria en rango nefrótico; en síndrome nefrítico o nefrótico y ante la duda diagnóstica que requiera confirmar presencia y grado de lesión renal [8]. Otro caso particular en el que se ha sugerido la biopsia renal es cuando se considera la donación del órgano de mujeres portadoras, con el fin de identificar riesgos del procedimiento tanto para el donante como para el receptor [9].

En caso de variantes genéticas de significado incierto, se considera que el estándar de oro para el diagnóstico de Fabry en pacientes con manifestaciones no específicas de la enfermedad debe ser la comprobación histológica que evidencie la acumulación de glicoesfingolípidos en uno de los órganos afectados [66]. 
Tabla 2. Recomendaciones sobre la evaluación inicial y el seguimiento para el paciente con enfermedad de Fabry

\begin{tabular}{|c|c|c|}
\hline Órgano/categoría & Evaluación & Seguimiento \\
\hline General & $\begin{array}{l}\text { Examen físico completo } \\
\text { Evaluación de la calidad } \\
\text { de vida } \\
\text { Asesoría genética }\end{array}$ & $\begin{array}{l}\text { En cada consulta } \\
\text { Al momento del } \\
\text { diagnóstico y } \\
\text { anualmente }\end{array}$ \\
\hline Riñón & $\begin{array}{l}\text { Calcular la TFG con las } \\
\text { fórmulas recomendadas } \\
\text { Medición en orina, cociente } \\
\text { albuminuria/creatinuria } \\
\text { Ecografía renal } \\
\text { Biopsia renal }\end{array}$ & $\begin{array}{l}\text { ERC estadios } 1 \text { y 2: cada año } \\
\text { ERC estadio 3: cada } 6 \text { meses } \\
\text { ERC } 4 \text { y } 5 \text { no dialítico: } \\
\text { cada } 3 \text { meses, se recomienda } \\
\text { utilizar CKD-EPI } \\
\text { Primera orina de la mañana } \\
\text { ERC estadio } 1 \text { y 2: cada año } \\
\text { ERC estadio 3: cada } 6 \text { meses } \\
\text { ERC } 4 \text { y } 5 \text { no dialítico: } \\
\text { cada } 3 \text { meses } \\
\text { Evaluar tamaño renal, } \\
\text { presencia } \\
\text { de quistes renales } \\
\text { Indicación clínica: } \\
\text { progresión rápida que no se } \\
\text { ajuste a la historia natural, } \\
\text { aumento súbito o no esperado } \\
\text { de la proteinuria, con el fin de } \\
\text { excluir otros diagnósticos, en } \\
\text { caso de variante de significado } \\
\text { compromiso renal }\end{array}$ \\
\hline
\end{tabular}




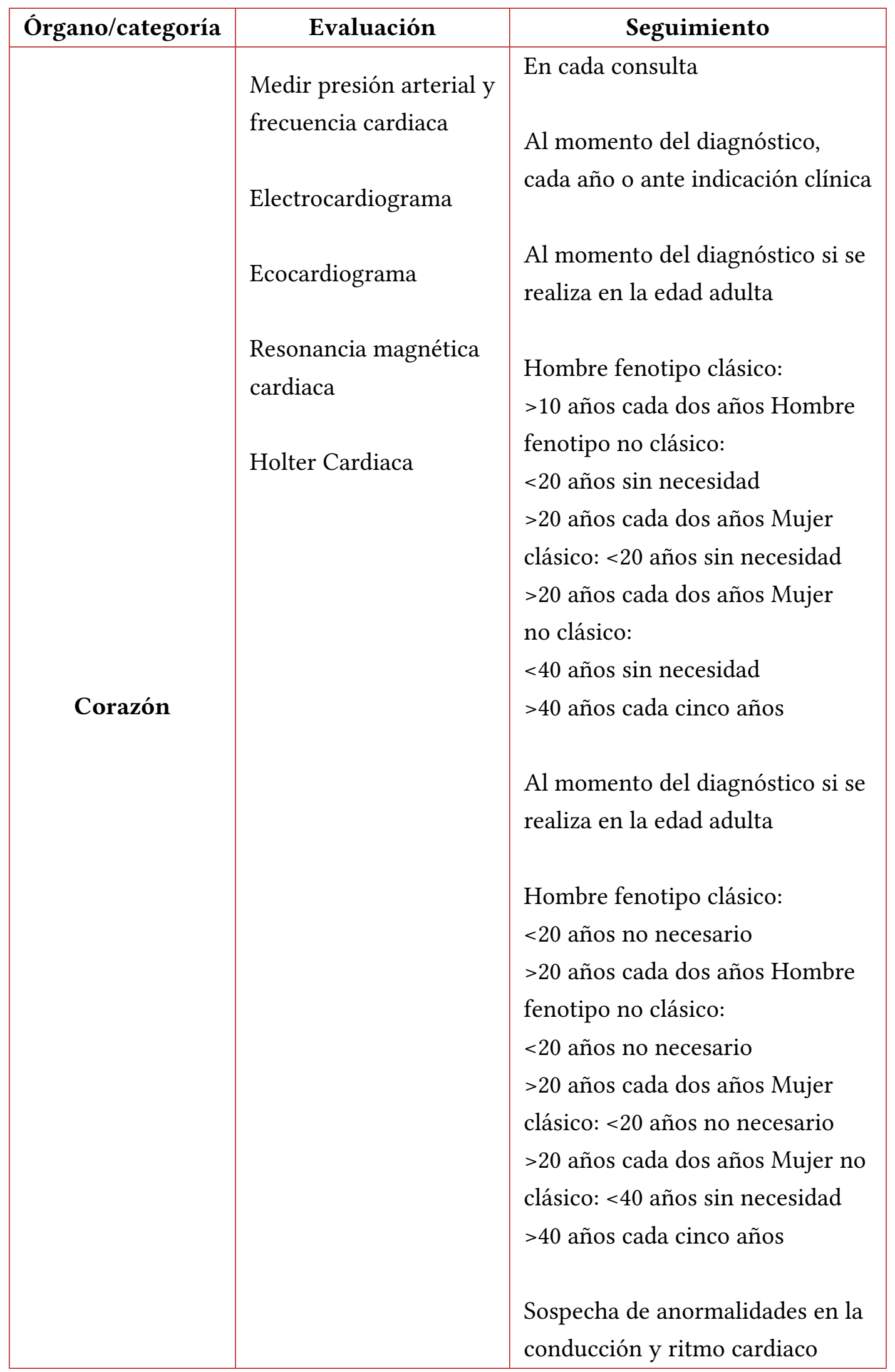




\begin{tabular}{|c|c|c|}
\hline Órgano/categoría & Evaluación & Seguimiento \\
\hline Sistema nervioso central & $\begin{array}{l}\text { Resonancia } \\
\text { magnética }\end{array}$ & $\begin{array}{l}\text { Al momento del diagnóstico si se } \\
\text { realiza en la edad adulta } \\
\text { Hombre fenotipo clásico: } 20-30 \text { años } \\
\text { cada tres años } \\
>30 \text { años cada dos años Hombre } \\
\text { fenotipo no clásico: } \\
<30 \text { años sin necesidad } \\
>30 \text { años cada cuatro años } \\
\text { Mujer clásico: } \\
<30 \text { años sin necesidad } \\
>30 \text { años cada cuatro años } \\
\text { Mujer no clásico: } \\
<40 \text { años sin necesidad } \\
>40 \text { años cada cinco años }\end{array}$ \\
\hline Dolor neuropático & & $\begin{array}{l}\text { Evaluación e historia del } \\
\text { dolor, medir escala del dolor }\end{array}$ \\
\hline Sistema gastrointestinal & $\begin{array}{l}\text { Historia clínica, interrogar } \\
\text { sobre hábitos intestinales, } \\
\text { náuseas/vómitos, aumento } \\
\text { de peso y dieta } \\
\text { Estudio de radiología o } \\
\text { endoscópico para excluir } \\
\text { otras causas de dolor }\end{array}$ & $\begin{array}{l}\text { Al momento del diagnóstico } \\
\text { y anualmente }\end{array}$ \\
\hline
\end{tabular}

\section{Recomendaciones}

- Se sugiere considerar la biopsia renal con microscopia electrónica en casos de progresión rápida que no se ajuste a la historia natural de la enfermedad, como en casos de pérdida rápida de la función renal o aumento súbito o no esperado de la proteinuria, con el fin de excluir otros diagnósticos como enfermedades glomerulares intercurrentes o nefrotoxicidad por medicamentos, entre otros.

\section{Fuerte a favor}

- En caso de variante de significado incierto en que haya compromiso renal, dado por alteraciones de la TFG o sedimento y en que la biopsia endomiocárdica no esté disponible.

\section{Débil a favor}




\section{¿Cuáles son los hallazgos histopatológicos en la biopsia renal?}

El hallazgo histopatológico característico en la enfermedad de Fabry con afectación renal corresponde a la vacuolización celular, producto de la acumulación de Gb-3 en el citoplasma de podocitos, las células epiteliales de los túbulos, las células endoteliales de los capilares peritubulares y la íntima vascular [3, 9, 12, 29,52]. Estos hallazgos se presentan tempranamente, antes de que aparezcan las manifestaciones clínicas, como cuerpos de inclusión osmófilos en el citoplasma de las células renales, con la apariencia característica de cuerpos mieloides y "cebra”. Cuando ya existe compromiso de la función renal hay presencia de glomeruloesclerosis, atrofia tubular y fibrosis intersticial, proliferación y engrosamiento mesangial y cambios vasculares $[12,29,51,52]$.

\section{Recomendaciones}

- La vacuolización celular en podocitos, mesangio y célula endotelial con acumulación de glicoesfingolípidos (cuerpos de cebra) es el principal hallazgo histopatológico temprano sugestivo de enfermedad de Fabry en la biopsia renal.

\section{Fuerte a favor}

- Se sugiere que la presencia de esclerosis glomerular focal, el engrosamiento mesangial, los cambios vasculares, la atrofia tubular y la fibrosis intersticial son signos de daño renal avanzado en enfermedad de Fabry.

\section{Fuerte a favor}

\section{¿Cuáles enfermedades glomerulares y tubulares son diagnóstico diferen- cial de la enfermedad de Fabry?}

Dentro de los diagnósticos diferenciales de la enfermedad de Fabry con afectación renal, a partir de hallazgos histológicos, se han descrito los siguientes: gangliosidosis GM1, enfermedad de células I, síndrome de Hurler, enfermedad de Niemann-Pick, enfermedad de Farber, enfermedad de Batten y nefrosialidosis infantil. También se ha considerado la lipidosis renal iatrogénica secundaria a medicamentos como cloroquina, hidroxicloroquina y amiodarona (los cuales se depositan en tejidos como hígado, bazo, pulmones y riñones), permitiendo la captura lisosómica y la inhibición de la enzima lisosomal a-galactosidasa A $[8,12,67]$.

\section{Recomendaciones}

- Se sugiere considerar como diagnóstico diferencial histopatológico de la variante renal de Fabry la gangliosidosis GM1, la enfermedad de células I, el síndrome de Hurler, la 
enfermedad de Niemann-Pick, la enfermedad de Farber y la enfermedad de Batten.

Fuerte a favor

- Debe considerarse descartar lipidosis renal por cloroquina, hidroxicloroquina, amiodarona, metadona, levomepromazina, promasina, amitriptilina, clozapina, eritromicina, fluoxetina, sertralina, entre otros.

Fuerte a favor

\section{Tratamiento}

\section{¿Cómo evaluar la respuesta al tratamiento de terapias de reemplazo en- zimático?}

Para hacer seguimiento a la respuesta renal de la TRE se han incluido: evaluación clínica, medición de albúmina, creatinina, TFG medida o estimada, relación albúmina:creatinina (UACR por siglas en inglés), TFGe, biopsia renal, estado y extensión de la podocituria, niveles de lyso-Gb3 y anticuerpos contra la TRE [36, 44, 52, 60, 65, 68].

En 2016, Mignani et al. propusieron la medición de desenlaces en Fabry mediante el uso de índice de estabilización que evalúa tres dominios: neurología, cuyos desenlaces fueron dolor y ACV; cardiopatía con desenlaces dados por clase funcional (NYHA) y parámetros ecocardiográficos y nefropatía, cuyos desenlaces fueron de grado de proteinuria y cambio en la tasa de filtración glomerular. Se considera "no variación" cuando hay menos del $20 \%$ de diferencia frente a la medición inicial. La aplicación de esta herramienta permite una evaluación objetiva de cada dominio [69]).

\section{Recomendaciones}

- Se recomienda evaluar la respuesta renal a la TRE con relación albuminuria:creatinuria y cambios de TFG estimada con fórmula CKD-EPI, considerando como valores de referencia los previos al inicio de la terapia.

\section{Fuerte a favor}

- Se sugiere considerar la realización de biopsia renal en pacientes con Fabry con terapia de reemplazo enzimático que presenten una evolución diferente a la esperada con relación a lo descrito en pacientes tratados.

\section{Débil a favor}




\section{¿Cuáles son los criterios desde el punto de vista renal para iniciar trata- miento de reemplazo enzimático?}

La TRE se considera una alternativa para la reducción de la progresión de enfermedad renal y aparición de complicaciones a largo plazo de la enfermedad de Fabry, por lo que su inicio temprano se ha considerado por diferentes autores [11, 29, 32, 36, 49, 52,70], ya que la respuesta al tratamiento disminuye, si los pacientes presentan proteinuria mayor de $1 \mathrm{gm} / \mathrm{día}$ o deterioro de la tasa de filtración glomerular (TFG $<60 \mathrm{ml} / \mathrm{min}$ ) en el momento del inicio.

El diagnostico de enfermedad de Fabry en ausencia de evidencia clínica de afectación de órganos no es indicación de terapia específica para la enfermedad [59].

El inicio de TRE se ha sugerido en casos de enfermedad renal con TFG preservada (TFGe $<80 \mathrm{ml} / \mathrm{min}$, proteinuria $>300 \mathrm{mg} /$ día) o albuminuria A2 (ACR/albuminuria orina 24 horas, por arriba de $30 \mathrm{mg} / \mathrm{g}$ ) o anormalidades en la biopsia renal evidenciada por presencia de depósitos [52].

En mujeres sintomáticas, la guía argentina recomendó iniciar TRE en casos de compromiso renal evidenciado por albuminuria, proteinuria o descenso de la TFGe en ausencia de otras causas o hallazgos histológicos típicos de la enfermedad de Fabry, como borramiento de procesos podocitarios e inclusiones de $\mathrm{Gl} 3$ intracitoplasmáticos en podocitos y endotelio capilar; mientras que en mujeres no sintomáticas se recomendó el inicio de la TRE ante el descenso de la TFGe $\left(<90 \mathrm{ml} / \mathrm{min} / 1,73 \mathrm{~m}^{2}\right.$, ajustado para la edad en mayores de 40 años), albuminuria persistente (A2 o A3) y lesiones en biopsia renal [49].

Asimismo, en el Consenso Centroamericano y del Caribe se sugirió el inicio o continuación de TRE en pacientes con terapia de soporte renal (TSR) como medida de protección de otros órganos y prevención de complicaciones, y también en casos de albuminuria A1 o proteinuria, hallazgos de depósitos de $\mathrm{Gl} 3$ con borramiento de los procesos podocitarios en la biopsia renal, aún previo al desarrollo de albuminuria/proteinuria [8].

En la guía de ERBP se desaconsejó el inicio de TRE en pacientes con proteinuria UACR mayor $1 \mathrm{~g} / \mathrm{g}$, TFGe menor de $60 \mathrm{ml} / \mathrm{min} / 1,73 \mathrm{~m}^{2}$ (1D) o trasplante renal, a no ser que sea indicada para condiciones no renales [9].

La guía canadiense 2019 recomendó su uso en pacientes que cumplan un criterio mayor o dos criterios menores [59]. Dentro de los criterios mayores se encuentran los que evidencian nefropatía clara, como presencia de: 
TFG reducida: TFG $<60 \mathrm{ml} / \mathrm{min} / 1,73 \mathrm{~m}$, IRC estadio 2 (entre 60 y $90 \mathrm{ml} / \mathrm{min} / 1,73 \mathrm{~m}^{2}$ ) hiperfiltración (TFG $>135 \mathrm{ml} / \mathrm{min} / 1,73 \mathrm{~m}^{2}$ ) con disminución del $15 \%$ de la TFG durante el seguimiento, proteinuria persistente mayor de $500 \mathrm{mg} /$ día y hallazgos en biopsia que indiquen patología renal con alto riesgo de progresión como esclerosis glomerular, atrofia tubulointersticial, fibrosis o esclerosis vascular (en hombres).

Los criterios renales menores [59] corresponden a hiperfiltración aislada mayor a 135 $\mathrm{ml} / \mathrm{min} / 1,73 \mathrm{~m}^{2}$, proteinuria aislada persistente de $300 \mathrm{mg} /$ día, disfunción tubular renal (síndrome de Fanconi o diabetes insípida nefrogénica) e hipertensión de al menos un año de duración. Se establece, además, que si se realiza biopsia renal en mujeres, los hallazgos histopatológicos antes mencionados también se consideran como criterio menor.

\section{Recomendaciones}

- Se sugiere el inicio de tratamiento con TRE en pacientes con Fabry diagnosticado, considerando también manifestaciones clínicas o daño a órgano blanco diferente a riñón.

\section{Opinión de expertos}

- Se recomienda iniciar la TRE ante la afectación renal por enfermedad de Fabry, evidenciada por (i) TFGe menor a $90 \mathrm{ml} / \mathrm{min}$ (ajustada a edad) confirmada en dos recolecciones de orina en mínimo dos meses o (ii) presencia de albuminuria persistente mayor a 30 $\mathrm{mg} / \mathrm{g}$ y confirmada con mínimo dos muestras y (iii) en caso de disponibilidad de biopsia renal, hallazgos de daño como fusión de procesos podocitarios, inclusiones y acúmulo de glicoesfingolípidos en varios tipos celulares.

\section{Fuerte a favor}

- Se sugiere considerar iniciar la TRE en casos de hiperfiltración (TFG $>135 \mathrm{ml} / \mathrm{min}$ ) y ante la disminución de pendiente de TFGe mayor al $15 \%$ respecto a medición inicial, medido por método isotópico. Fuerte a favor

- Se sugiere considerar la TRE en pacientes con terapia de soporte renal (TSR) para proteger otros órganos y prevenir complicaciones, posterior a evaluación clínica y análisis de potencial beneficio clínico para el paciente.

\section{Débil a favor}

- En caso de Fabry de inicio tardío se sugiere comprobación clínica, paraclínica (lyso-Gb3) e histológica en presencia de indicadores de daño renal para excluir otros diagnósticos, antes de iniciar TRE.

\section{Fuerte a favor}




\section{¿Existen otros tratamientos para evitar la progresión renal?}

A pesar de que el tratamiento de la enfermedad de Fabry se basa en la administración de terapia de remplazo enzimático con agalsidasa- $\alpha$, agalsidasa- $\beta$ y recientemente de chaperonas farmacológicas en pacientes con mutaciones específicas, para disminuir la acumulación de sustrato y, por consiguiente, la lesión en los órganos blanco, esto no quiere decir que no se empleen estrategias que han demostrado disminuir la pérdida de función renal como los inhibidores de enzima convertidora de angiotensina y los bloqueadores del receptor AT1 de la angiotensina II, especialmente cuando los pacientes presentan proteinuria o hipertensión $[9,36,52,63,68]$.

Por consiguiente, se ha sugerido que pacientes con albuminuria o proteinuria deben recibir concomitantemente IECA o ARA-2, buscando una proteinuria objetivo menor a 0,5 $\mathrm{g} / 24$ horas y una albuminuria menor a $300 \mathrm{mg} / 24$ horas [60].

Otras medidas de nefroprotección no específicas incluyen: mantener una hidratación adecuada, un control de los factores de riesgo de progresión de enfermedad renal, tales como la hipertensión arterial y la anemia [8] y evitar la exposición a fármacos nefrotóxicos y en lo posible a medios de contraste.

\section{Recomendaciones}

- A pesar de avances en nuevos tratamientos para la enfermedad de Fabry, aún no es posible recomendar una alternativa específica, diferente a las ya conocidas como TRE y chaperonas.

\section{Opinión de experto}

- En pacientes con excreción anormal de proteínas en la orina, se sugiere el uso de IECAS o ARA II como estrategia coadyuvante para disminuir la velocidad de progresión del daño renal.

\section{Fuerte a favor}

- Se recomienda en todos los pacientes con Fabry adoptar medidas de nefroprotección demostradas para retrasar la progresión del daño renal, incluyendo actividad física, dieta hiposódica, control de sobrepeso, lípidos e hiperglicemia, cesar tabaquismo, entre otras. Fuerte a favor

- Se sugiere educar a los pacientes para evitar automedicación y uso inadvertido o prescrito de medicamentos con potencial de nefrotoxicidad, incluyendo medios de contraste 
y antiinflamatorios no esteroideos, entre otros.

\section{Fuerte a favor}

\section{¿Cuál es la indicación de chaperonas?}

En relación al manejo de pacientes con enfermedad de Fabry con la medicación oral con chaperonas (migalastat), los estudios sobre seguridad y efectividad establecen su indicación en pacientes con una mutación susceptible, referenciada en las bases de datos de los estudios aprobados por EMEA, con edad superior a 16 años y una TFGe superior a $30 \mathrm{ml} / \mathrm{min} / 1,73$ $\mathrm{m}^{2}[71,72]$.

El estudio fase 3 de Germain et al. de 2016, realizado en pacientes con enfermedad de Fabry con una mutación susceptible, se realizó con el objetivo de evaluar el efecto de migalastat vs. placebo después de 6 meses de tratamiento (fase 1) sobre los depósitos de lyso-Gb3 en los capilares peritubulares del riñón y establecer los niveles de Gb3 urinarios y el cambio en la función renal, con extensión del estudio a una fase 2 a tiempo de 6-12 meses y 12-24 meses para los pacientes que completaran la fase 1 [72].

Los 50 pacientes estudiados se clasificaron como fenotipo clásico en un $60 \%$, no clásico $2 \%$, ambos en $6 \%$ y en un $32 \%$ mutaciones no clasificadas, con una edad entre 16 y 74 años, sin haber recibido TRE previa o al menos en los últimos seis meses y niveles de Gb-3 urinario mayor o igual a cuatro veces el valor normal; el $94 \%$ de los pacientes tenía concentraciones altas de lyso-Gb3 en plasma y el $94 \%$ tenía afectación en al menos dos órganos. Los resultados en los hallazgos histológicos entre los grupos arrojaron una diferencia media de 7,3 puntos porcentuales a favor del migalastat $(\mathrm{p}=0,04)$ vs. placebo, efectos que se extendieron a los 12 meses de seguimiento en tratamiento con migalastat. En cuanto la media de la TFG estimada a los 6 meses, no se presentó diferencia significativa entre los grupos y a los 12-24 meses la reducción anual en la TFGe fue de $-0,30 \pm 0,66 \mathrm{ml} / \mathrm{min} / 1,73 \mathrm{~m}^{2}$ y $-1,51 \pm 1,33 \mathrm{ml} / \mathrm{min} / 1,73$ $\mathrm{m}^{2}$, respectivamente. La disminución de la función renal se asoció con el sexo masculino y proteinuria elevada. Con respecto al grado de proteinuria no se presentaron diferencias significativas entre ambos grupos [72].

En un estudio en un único centro, con una cohorte de 21 pacientes con enfermedad de Fabry, se realizó seguimiento durante un año para valorar la eficacia en el cambio de actividad enzimática y biomarcadores con la terapia oral con chaperona, migalastat. Un subgrupo de 6 $(28,6 \%)$ de los pacientes había recibido previamente terapia de reemplazo enzimático (TRE) y fueron cambiados a terapia oral. La edad promedio de los pacientes fue de 51,7 + 14,9 años, el $61,9 \%$ eran hombres, el 52,4\% con fenotipo de inicio tardío. El promedio de concentración de 
lyso-Gb3 fue de $9 \mathrm{ng} / \mathrm{ml}$, la creatinina de $0,9 \mathrm{mg} / \mathrm{dl}$ (RIQ 0,83-1,05) y la mediana de TFGe fue de $85 \mathrm{ml} / \mathrm{min} / 1,73 \mathrm{~m}^{2}$ (RIQ 75,5-98) [73].

Los resultados encontrados con migalastat fueron que la actividad enzimática pasó de 0,06 $\mathrm{nmol} / \mathrm{min} / \mathrm{mg}(\mathrm{IQR} 0,04-0,12)$ a $0,2 \mathrm{nmol} / \mathrm{min} / \mathrm{mg}(\mathrm{IQR} \mathrm{0,06-0,26)}(\mathrm{P}=0,001)$. En cuanto a los valores de concentración de lyso-Gb3, estos permanecieron estables en general, sin embargo, en cinco pacientes se presentó un incremento de lyso-Gb3, con mayor proporción en hombres que previamente habían recibido TRE en la niñez (cambio de lyso-Gb3 de 12,46 a 66,1 ng/ml). La mediana de TFGe fue de $72 \mathrm{ml} / \mathrm{min} / 1,73 \mathrm{~m}^{2}$ (RIQ 65-78) con una creatinina de 1,09 $\mathrm{mg} / \mathrm{dL}$ $(1,05-1,2)$. En el subgrupo que recibió TRE, la actividad enzimática pasó a $0,14 \mathrm{nmol} / \mathrm{min} / \mathrm{mg}$ (RIQ 0,06-0,25) ( $\mathrm{p}=0,016)$ y la mediana fue de TFGe a $78 \mathrm{ml} / \mathrm{min} / 1,73 \mathrm{~m}^{2}$ (RIQ 71,5-99), con una creatinina de $1,0 \mathrm{mg} / \mathrm{dL}$ (RIQ 0,87-1,11) [73].

En el estudio clínico aleatorizado ATTRACT a 18 meses, se evalúo en pacientes con enfermedad de Fabry con mutación del GLA susceptible al migalastat el efecto sobre la función renal comparados con TRE. Los pacientes se clasificaron de acuerdo con el fenotipo en clásico $36 \%$, no clásico $40 \%$, ambos $4 \%$ y no clasificado $21 \%$, tenían un esquema de TRE iniciado al menos de 12 meses previos a la visita inicial y una TFG estimada (TFGe) $\geq 30$ $\mathrm{ml} / \mathrm{min} / 1,73 \mathrm{~m}^{2}$. En total se incluyeron 57 pacientes en los análisis. La edad promedio fue de 48,9 + 1,9 años con rango entre 18 y 72 años, con $56 \%$ mujeres, el promedio de tiempos desde el diagnóstico fue de 11,4 + 1,6 años. El cambio anualizado de TFGe en 18 meses de seguimiento fue de $-1,51+0,95 \mathrm{ml} / \mathrm{min} / 1,73 \mathrm{~m}^{2}$ en el grupo con migalastat, mientras que para la TRE fue de $-1,53 \pm 1,32 \mathrm{ml} / \mathrm{min} / 1,73 \mathrm{~m}^{2}$. Respecto a la TFG medida, el cambio anualizado fue de $-4,35 \pm 1,64$ con migalastat y de $-3,24 \pm 2,27$ con TRE. Es importante resaltar que estudios previos de pacientes tratados con TRE reportan progresión del deterioro de la TFG en -2,2 a $2,9 \mathrm{cc} / \mathrm{min}$ año. El cambio medio de proteína en orina de 24 horas fue de 49,2 $\mathrm{mg}$ en el grupo de migalastat y de 194,5 mg en el grupo de TRE [74].

\section{Recomendaciones}

- A pesar de que la terapia con chaperona (migalastat) es prometedora para el manejo de enfermedad de Fabry, su eficacia aún es controvertida, por lo que se sugiere el uso de tratamiento oral con chaperonas (migalastat) en pacientes mayores de 16 años con enfermedad de Fabry con una mutación susceptible confirmada y una TFGe superior a $30 \mathrm{ml} / \mathrm{min} / 1,73 \mathrm{~m}^{2}$.

\section{Débil a favor}




\section{¿Existe diferencia entre las terapias de reemplazo enzimático en resulta- dos renales?}

La terapia de reemplazo enzimático es el estándar en el manejo de la enfermedad de Fabry desde la aprobación de ambas moléculas: agalsidasa- $\alpha$ y agalsidasa- $\beta$, por la EMEA y la agalsidasa $\beta$ por la FDA, para inicio en los pacientes desde los 7 años [75].

En sus estudios primarios establecieron una dosificación de $0,2 \mathrm{mg} / \mathrm{kg} /$ cada dos semanas y $1 \mathrm{mg} / \mathrm{kg} / \mathrm{cada}$ dos semanas, respectivamente. Una revisión sistemática de El Dib et al. en 2016 evalúo la efectividad y la seguridad de la TRE con agalsidasa- $\alpha$ y agalsidasa- $\beta$ comparado con placebo y otras intervenciones o ninguna. Se estableció una mejoría significativa en los depósitos endoteliales de Gb3 con TRE comparados con placebo, sin evidenciar diferencias en la eficacia entre las dos moléculas en relación con la dosis o las frecuencias. En esta revisión, dos estudios agruparon 184 participantes y compararon la agalsidasa- $\alpha$ con la agalsidasa- $\beta$, sin embargo, solo un estudio reportó un desenlace renal, indicando que en dos pacientes tratados con agalsidasa- $\alpha$ se observó progresión de la insuficiencia renal [75].

El estudio de Sirrs et al., de 2014, reportó los resultados de cinco años de seguimiento de tres cohortes de pacientes canadienses entre 5 y 85 años con enfermedad de Fabry. La primera cohorte incluyó pacientes $(n=86)$ en tratamiento con TRE, la segunda cohorte consistió en pacientes $(n=67)$ con uso reciente de TRE y aleatorizados a agalsidasa- $\alpha$ o $\beta$, aunque en el periodo de escasez de agalsidasa- $\beta$, los pacientes fueron cambiados a agalsidasa- $\alpha$ y la tercera cohorte fue de pacientes $(n=209)$ sin indicación de TRE, de los cuales 25 durante el seguimiento cumplieron criterios para el inicio de TRE y fueron reasignados a la segunda cohorte [76].

El desenlace de interés principal fue el resultado clínico compuesto que incluyó evento renal, definido como desarrollo de enfermedad renal estadio 5 o disminución del $50 \%$ de TFG durante 30 días continuos sin otra causa aparente; evento cardiovascular, cerebrovascular o muerte. Los hallazgos reportados incluyen a 362 pacientes adultos, 178 fueron finalmente tratados con TRE, se presentaron menos eventos en la segunda cohorte (inicio reciente) respecto a las otras dos $(\mathrm{p}<0,05)$, asimismo, dentro de esta cohorte se presentó el desenlace compuesto en el 19,4\% de los pacientes tratados con agalsidasa- $\alpha$ y en 13,3\% de los pacientes tratados con agalsidasa, sin diferencia significativa $(p>0,05)[76]$.

En la cohorte multicéntrica descrita por Arends et al. se comparó el efecto de la agalsidasa$\alpha$ frente a la $\beta$ sobre desenlaces clínicos y bioquímicos en pacientes canadienses y europeos 
con diagnóstico confirmado de Fabry y que habían recibido agalsidasa- $\alpha$ a una dosis de 0,2 $\mathrm{mg} / \mathrm{kg} /$ cada dos semanas o agalsidasa- $\beta$ a una dosis de $1,0 \mathrm{mg} / \mathrm{kg} /$ cada dos semanas, durante al menos nueve meses. Respecto a los desenlaces clínicos renales, se evaluó el evento renal (ERC estadio 5) y la función renal. El análisis incluyó a 387 pacientes, 37\% europeos, 56\% hombres, la edad promedio de inicio de la TRE fue de $46 \pm 15$ años. El $67 \%$ recibió agalsidasa- $\alpha$, la mediana del seguimiento fue de 4,9 (RIQ 0,8-14,4) años. Los pacientes con agalsidasa- $\beta$ se caracterizaron por enfermedad clásica, antecedente de trasplante renal o diálisis, mayor concentración de lyso-Gb3 y TFGe más baja al inicio del estudio. La mediana de TFGe en el grupo de agalsidasa- $\alpha$ al inicio del seguimiento fue de 89 (RIQ 10-159) $\mathrm{ml} / \mathrm{min} / 1,73 \mathrm{~m}^{2}$ y el $23 \%$ tenía ERC3, mientras que en los pacientes del grupo de agalsidasa- $\beta$ la mediana de TFGe fue de 86 (RIQ 10-140) ml/min/1,73 $\mathrm{m}^{2}$ y el $37 \%$ tenía ERC3. Ambos grupos de pacientes recibieron medicamentos IECA y ARA-2. Los resultados renales se basan en 337 pacientes y no se encontró diferencia entre los grupos para el cambio de TFGe ( $p=0,70)$; sin embargo, se presentó progresión a desenlace compuesto (renal, cardiovascular, ACV o muerte) en el 19,4\% de los pacientes tratados con agalsidasa- $\alpha$ versus $13,4 \%$ de los tratados con agalsidasa- $\beta$ ( $\mathrm{p}=$ $0,57)[77]$.

Najafian et al. demostró, con el uso de medición estereológica con microscopia electrónica, una reducción en el $73 \%$ del contenido de Gl3 podocitario y una reducción del $63 \%$ del volumen podocitario en pacientes tratados por un año con agalsidasa- $\beta 1 \mathrm{mg} / \mathrm{kg} / \mathrm{bisemanal} \mathrm{[78].}$

Es importante resaltar que la dosis de remplazo enzimático tiene efecto sobre el aclaramiento de Gl3 podocitario [79]. Skrunes et al. encontraron que la disminución de la dosis de agalsidasa ocasiona una reacumulación de Gl3 en podocitos y que el inicio de terapia antes de los siete años, comparado con el inicio posterior a los 18 años, produce un mejor aclaramiento del Gl3 podocitario [44]. Estos resultados son importantes porque se ha demostrado que la acumulación de este sustrato se asocia con la pérdida podocitaria progresiva, proteinuria y, por consiguiente, con la pérdida de la función renal [80].

Lenders et al., en un estudio observacional de 89 pacientes Fabry con dos años de seguimiento, que evaluó daño a órgano blanco y sintomatología, encontraron que los pacientes que requirieron cambio de agalsidasa- $\alpha$ o reducción de dosis de agalsidasa- $\beta$ a consecuencia del desabastecimiento mundial de $\beta$, mostraron un mayor deterioro en la TFG, que fue de $-3,74$ $\mathrm{ml} / \mathrm{min} / 1,73 \mathrm{~m}^{2} /$ año, que los pacientes que continuaron en $\beta$ a dosis completa de $1 \mathrm{mg} / \mathrm{kg} / \mathrm{dos}$ semanas, los cuales permanecieron con TFG estable [81]. 
En 2020, Lenders et al. [82] publicaron los resultados de un estudio prospectivo observacional con seguimiento de 88 meses, confirmaron que los pacientes que permanecieron en dosis completa de agalsidasa- $\beta$ ( $1 \mathrm{mg} / \mathrm{kg} /$ dos semanas), permanecieron con TFG estable, mientras que los pacientes a los que se cambió a agalsidasa- $\alpha$ y posteriormente regresaron a tratamiento con beta a dosis completa y los que permanecieron con alfa a dosis de $0,2 \mathrm{mg} / \mathrm{kg} / \mathrm{dos}$ semanas mostraron un deterioro en la TFG, con una pérdida anual en el caso de los hombres de $-2,5$ y $-3,9 \mathrm{ml} / \mathrm{min} / 1,73 \mathrm{~m}^{2}$. En las mujeres solo se evidenció deterioro en la TFG de $-2,9 \mathrm{ml} / \mathrm{min} / 1,73$ $\mathrm{m}^{2}$ en las pertenecientes al grupo de cambio a alfa y posterior regreso a beta a dosis completa. Los niveles de lyso-Gb3 disminuyeron en los pacientes que regresaron a $\beta$ dosis completa después de haber sido tratados con agalsidasa- $\alpha$ [82].

\section{Recomendaciones}

- La evidencia disponible no permite establecer una diferencia consistente entre los dos tratamientos de reemplazo enzimático: agalsidasa- $\alpha$ y agalsidasa- $\beta$, sobre desenlaces renales.

\section{Sin gradar}

- Algunos estudios sugieren un beneficio mayor en la mejoría de los hallazgos histológicos y la disminución de progresión de la pérdida de TFG en pacientes con tratamiento con agalsidasa- $\beta$ dosis a $1 \mathrm{mg} / \mathrm{kg} / \mathrm{dos}$ semanas.

\section{Sin gradar}

\section{¿Cuál es el impacto clínico de los anticuerpos contra la terapia enzimá- tica?}

La síntesis de anticuerpos contra las preparaciones enzimáticas de agalsidasa $\alpha$ o $\beta$ se da como resultado del reconocimiento por parte del sistema inmune de una sustancia no producida en el organismo [52], que puede afectar al $40 \%$ de los hombres dentro de los seis primeros meses de inicio de la terapia de sustitución y se relaciona con la disminución de la eficacia del tratamiento.

Se ha descrito que los pacientes tratados con agalsidasa- $\beta$ tienen mayor posibilidad de producir anticuerpos de inmunoglobulina G (IgG), la cual se da entre el 40 y el $73 \%$ de los casos. Entre los tratados con agalsidasa- $\alpha$ se producen en el $24 \%$ [83]; sin embargo, recientemente se ha establecido que el principal factor de riesgo para el desarrollo de anticuerpos es tener una mutación nonsense y no depende del tipo de agalsidasa [13]. Los anticuerpos neutralizantes permanecen por periodos variables de tiempo y pueden disminuir la eficiencia de la terapia, evidenciada por aumento en los niveles de lyso-GB3 comparados con el periodo anterior al desarrollo de los mismos [83]. 
En la cohorte de Arends et al., en hombres con fenotipo clásico se encontró que, a pesar de que el tratamiento con agalsidasa- $\beta$ aumenta la posibilidad de desarrollar anticuerpos cerca de tres veces (OR 2,8 p = 0,04) en comparación con los tratados con alfa, el efecto de agalsidasa- $\beta$ sobre la disminución en la concentración plasmática de lyso-Gb3, aún en presencia de anticuerpos, fue significativamente mayor que en los que se trataron con agalsidasa- $\alpha$ [77].

Lenders et al. [26] describieron en 26 hombres con fenotipo clásico que el efecto de los anticuerpos neutralizantes (IgG4 principalmente) sobre los desenlaces clínicos depende del nivel de saturación enzimática. Se definió a los pacientes como saturados cuando se encontraron niveles de agalsidasa mayores de los necesarios para saturar los anticuerpos, se definió como saturación a la cantidad de enzima necesaria para reducir la capacidad de neutralización de 5 microgramos de IgG del paciente por debajo del umbral de neutralización enzimática de $10 \%$. Los pacientes saturados tuvieron pérdida de TFG de $3 \mathrm{ml} / \mathrm{min}$ año mientras que los no saturados perdieron $-4,8 \mathrm{ml} / \mathrm{min}$ año; el nivel de lyso plasmático disminuyó en 24,9 $\mathrm{ng} / \mathrm{min} / \mathrm{año}$ en pacientes saturados versus $7,9 \mathrm{ng} / \mathrm{ml} / \mathrm{año}$ en los no saturados; finalmente, el grosor del septum cardiaco disminuyó en $0,2 \mathrm{~mm} /$ año en los saturados, en comparación con un aumento de $0,4 \mathrm{~mm} /$ año en los no saturados [26].

El incremento en la dosis de terapia enzimática puede ocasionar un aumento en títulos de anticuerpos, a pesar de esto, permitió alcanzar el estado de saturación, lo cual a su vez se asoció con menores niveles de lyso-Gb3. La titulación frente a $\alpha$ o $\beta$ no mostró diferencia en la capacidad de saturar anticuerpos. El uso de agalsidasa- $\beta$ se asoció con títulos ligeramente mayores de anticuerpos comparados con alfa, sin embargo, la cantidad de dosis que permitió saturar los anticuerpos fue más cercana a la dosis estándar para $\beta$ (74 mg) que para alfa (60 $\mathrm{mg}$ ), considerando un paciente de $70 \mathrm{~kg}$ [26].

\section{Recomendaciones}

- Se sugiere considerar la medición de anticuerpos en pacientes que, a pesar de tratamiento ininterrumpido, presentan evolución tórpida, deterioro de función renal evidenciada en TFGe o aumento de lyso-Gb3. Débil a favor

- Se sugiere medir los títulos de anticuerpos contra la TRE al menos una vez al año y, en caso de ser positivos, medir también el lyso-Gb3. En caso de que el paciente este siendo tratado con agalsidasa- $\alpha$, considérese un cambio a agalsidasa- $\beta$ a dosis estándar. Opinión de expertos

- Se sugiere mantener dosis de agalsidasa- $\beta$ antes que cambiar o modificar de TRE, ante la presencia de anticuerpos neutralizantes. Fuerte a favor 


\section{¿Cuándo está indicada el cambio de terapia?}

Al realizarse la revisión de la literatura no se encontró evidencia que responda esta pregunta. La única información disponible corresponde al reporte de estudios observacionales acerca del cambio de la agalsidasa- $\beta$ a la agalsidasa- $\alpha$ debido a la escasez global ocurrida entre los años 2009 y 2012, debido a una contaminación viral, pero en estos estudios se realizó el cambio de terapia más por un desabastecimiento de la agalsidasa- $\beta$ más que por una indicación clínica o falla en el tratamiento [84-87].

En el estudio de Skrunes et al. en 2017, se reportó cambio de terapia de agalsidasa- $\alpha$ a $\beta$ debido a signos de nefropatía progresiva, miocardiopatía o efecto del tratamiento subóptimo, sin embargo, no se especifican los resultados del cambio [44].

En la cohorte alemana de pacientes con Fabry se evalúo a largo plazo el efecto de la estabilidad clínica y la seguridad después del cambio a agalsidasa- $\alpha$ y de retomar la dosis estándar de agalsidasa- $\beta$ sobre los eventos clínicos, daño renal en estadio final y síntomas clínicos relacionados con la enfermedad. Se consideraron tres grupos de exposición: (i) grupo de dosis regular que mantenía el esquema con agalsidasa- $\beta$, (ii) grupo de cambio que migró hacia terapia con agalsidasa- $\alpha$ y (iii) grupo de recambio que, a pesar de recibir en un periodo agalsidasa- $\alpha$, retorna al esquema con agalsidasa- $\beta$ [84].

El promedio de edad de los pacientes fue de $45+13$ años, la mayoría de los pacientes fueron hombres $(62 \%)$, la duración promedio de la TRE fue de $31+29$ meses. La terapia concomitante con bloqueadores del RAAS, diuréticos y analgésicos fue común, asimismo la presencia de anticuerpos positivos. El 8,1\% había recibido trasplante renal, $16 \%$ se encontraba en hemodiálisis y $11 \%$ tenía hiperfiltración. La creatinina promedio al inicio del seguimiento fue de 1,6 + 2,0 mg/dL, la TFGe fue de $80+39 \mathrm{ml} / \mathrm{min} / 1,73 \mathrm{~m}^{2}$, la mediana de la relación albúmina:creatinina fue de 96 (RIQ 14- 651) mg/g y el $38 \%$ tenía albuminuria. Sin considerar pacientes con trasplante, diálisis o hiperfiltración, la creatinina promedio fue de $1,1+0,5$ $\mathrm{mg} / \mathrm{dL}$ y la TFGe fue de $90+36 \mathrm{ml} / \mathrm{min} / 1,73 \mathrm{~m}^{2}$. Al final del tercer año de seguimiento se reportó que la TFGe de los pacientes del grupo de dosis regular se mantuvo estable, mientras que en el grupo de cambio hubo una reducción de la TFGe anual de $6,0+5,1 \mathrm{ml} / \mathrm{min} / 1,73$ $\mathrm{m}^{2} /$ año $(\mathrm{p}<0,05)$ y en el grupo de recambio de $5,8+8,9 \mathrm{ml} / \mathrm{min} / 1,73 \mathrm{~m}^{2} /$ año $(\mathrm{p}<0,05)$, mientras que al final del cuarto año el cambio promedio anual del grupo de cambio fue de $-4,6$ $+9,1 \mathrm{ml} / \mathrm{min} / 1,73 \mathrm{~m}^{2}$ y en el grupo de recambio fue de $-2,2+4,4 \mathrm{ml} / \mathrm{min} / 1,73 \mathrm{~m}^{2} /$ año [84] 


\section{Recomendaciones}

- Antes de decidir un cambio en el tratamiento, se sugiere considerar descartar otros factores que influyan en los desenlaces tales como adherencia, entrega y aplicación cumplida de la medicación.

\section{Fuerte a favor}

- Se sugiere documentar la elevación de lyso-Gb3 que puede asociarse con presencia de anticuerpos que interfieran con la efectividad del tratamiento.

\section{Débil a favor}

- En caso de anticuerpos neutralizantes contra TRE positivos se sugiere considerar cambio de agalsidasa- $\alpha$ 0,2 mg/ $/ \mathrm{kg} /$ dos semanas a agalsidasa- $\beta$ dosis de $1 \mathrm{mg} / \mathrm{kg} /$ dos semanas y en caso de encontrarse en esquema de tratamiento con agalsidasa- $\beta$ se sugiere mantener la dosis.

\section{Débil a favor}

- En caso de que el paciente tenga mala evolución clínica o aumento de lyso-Gb3 en esquema de agalsidasa- $\alpha$ o $\beta$ con dosis de $0,2 \mathrm{mg} / \mathrm{kg} / \mathrm{dos}$ semanas, se sugiere cambio a agalsidasa- $\beta$ dosis estándar.

Débil a favor

\section{¿Cuál es el valor del lyso-Gb3 en enfermedad de Fabry? ¿ ¿cuál es la in- terpretación del lyso-Gb3 en el diagnóstico y seguimiento de enfermedad \\ de Fabry?}

Los Gb3, incluido el lyso-Gb3, son biomarcadores con un potencial papel en la estratificación del riesgo, la distinción de fenotipos y el seguimiento de la enfermedad de Fabry [44,70]; sin embargo, es importante tener en cuenta que sus niveles no siempre están elevados en pacientes con variantes tardías o en mujeres, por lo que su medición rutinaria o diagnóstica no ha sido ampliamente recomendada [8].

La TRE ocasiona cambios en las concentraciones de lyso-Gb3, por lo que su medición podría aportar en el seguimiento y la respuesta al tratamiento [44,52], aunque se requiere más investigación para validar al lyso-Gb3 como biomarcador de seguimiento de tratamiento en enfermedad de Fabry. Además, su elevación durante el tratamiento puede sugerir la aparición de anticuerpos neutralizantes que comprometan la eficacia de la terapia enzimática [83].

En la cohorte danesa, el valor de lyso-Gb3 fue considerado anormal cuando era mayor de $0,5 \mathrm{ng} / \mathrm{ml}$. A pesar de la normalización de Gb3 con la TRE, las mediciones de lyso-Gb3 
permanecieron anormales en el $34 \%$ de los casos en una mediana de seguimiento de siete años. Valores normales se asociaron con una mejor función renal $(p<0,05)$ [36].

En el análisis post hoc liderado por Bichet et al., en 2021, se incluyeron en total 97 pacientes con y sin manejo previo con TRE, que habían participado en los ensayos clínicos FACETS y ATTRACT, con el fin de evaluar la utilidad del lyso-Gb3 durante el seguimiento de la respuesta al tratamiento con migalastat. El promedio de edad de los pacientes fue de 46,2 + 13,1 años, el $62 \%$ eran mujeres y el tiempo de diagnóstico promedio fue de $9+10,5$ años, promedio de exposición a TRE entre quienes ya la habían recibido de 3,4 + 2,4 años y mediana de duración de migalastat de 5,1 años (RIQ 0,1-8,5). No se encontró correlación entre los niveles de lyso-Gb3 y los eventos clínicos asociados a Fabry en pacientes analizados [88].

\section{Recomendaciones}

- Se sugiere considerar concentraciones de lyso-Gb3 superiores a 0,5 ng/ml en fenotipo clásico, como niveles altos que potencialmente favorecen el daño renal en pacientes con enfermedad de Fabry.

\section{Fuerte a favor}

- En caso de variantes tardías o en mujeres, los niveles de lyso-Gb3 pueden no estar relacionados directamente con la progresión de daño de órgano blanco.

\section{Fuerte a favor}

- Se sugiere considerar el lyso-Gb3 como biomarcador de seguimiento en enfermedad de Fabry con fenotipo clásico al menos dos veces por año, correlacionando su resultado con el cuadro clínico y la evaluación integral.

\section{Fuerte a favor}

- Se sugiere interpretar con precaución los niveles de lyso-Gb3 en la evaluación de tratamiento con chaperonas. Debe tenerse en cuenta la evolución clínica y otros marcadores de deterioro.

\section{Fuerte a favor}

\section{Financiación}

Este consenso de expertos sobre enfermedad de Fabry con compromiso renal recibió financiación por las farmacéuticas: Takeda, Sanofi y Pint Pharma, las cuales no han participado en ninguna de las fases del diseño, toma de decisiones, elaboración del material, análisis de la bibliografía, selección de los miembros del panel, dinámica del mismo, ni elaboración del informe de consenso final. 


\section{Conflicto de interés}

En la siguiente tabla aparecen los conflictos de interés declarados por algunos autores, también aparecen aquellos autores que aclararon no tienen conflictos de interés.

\begin{tabular}{|c|c|}
\hline Participante & Conflicto de interés declarado \\
\hline Luis Ramón Barros & Ninguno \\
\hline Sandra Juliana Jiménez & $\begin{array}{l}\text { Novartis, Pfizer, Genzyme, Shire: } \\
\text { - Congreso Americano de Trasplantes desde } 2004 \text { a } 2017 . \\
\text { - Kidney Week 2013-2018 }\end{array}$ \\
\hline Angélica Roncallo & $\begin{array}{l}\text { 1) Actividad educativa dictada para la compañía Sanofi en } \\
\text { el } 2019 \text { y expositor en Hipertensión Arterial } \\
\text { 2) Actividad educativa desarrollada para compañía Boydorr } \\
\text { Nutrition en el año } 2020 \\
\text { 3) Patrocinio para participar en el Simposio Nefrología al Día } \\
\text { en un Día por la compañía Takeda, años } 2020 \text { y } 2021 \\
\text { 4) Patrocinio de la compañía Sanofi para la actividad educativa } \\
\text { REEF 2019-2020 PAGE \* } \\
\text { 5) Patrocinio para participar en el Congreso Mundial de } \\
\text { Nefrología } 2017 \text { por parte de la compañía Fresenius Kabi }\end{array}$ \\
\hline Francisco López & $\begin{array}{l}\text { Sanofi Genzyme: } \\
\text {-Noviembre 2020: caso clínico de Fabry en la plataforma Sofi } \\
\text { - Junio 2020: conferencia en el Dart Board Terapias en Fabry } \\
\text { Sanofi Genzyme: } \\
\text {-Octubre 2019: capacitación a médicos generales en } \\
\text { enfermedad de Fabry }\end{array}$ \\
\hline Juan Carlos Conde & Ninguno \\
\hline Theo Martínez & Ninguno \\
\hline John Mauricio Lopera Vargas & Ninguno \\
\hline Manuel Garzón & $\begin{array}{l}\text { Sanofi y Genzyme: } \\
\text {-Junio 2019: X Simposio Internacional de Nefrología y } \\
\text { Trasplante Renal } \\
\text { - Entrenamiento a visitadoras medicas en } 2019\end{array}$ \\
\hline Kelly Rocío Chacón Acevedo & Ninguno \\
\hline Juan Politei & $\begin{array}{l}\text { En los últimos } 19 \text { años ha recibido honorarios por disertaciones } \\
\text { y ha sido consultor de } \\
\text { Biomarin, Sanofi, Pint, Amicus, Idorsia y Protalix }\end{array}$ \\
\hline Sebastián Jaurretche & $\begin{array}{l}\text { Ha recibido soporte científico de las siguientes empresas: } \\
\text { Sanofi-Genzyme Corp., Shire HGT, Pint Pharma, BioMarin, } \\
\text { Novartis, Gador, Pfizer, Sandoz, Boehringer Ingelheim, } \\
\text { Bristol-Myers Squibb, Amicus Therapeutics, Pint Pharma, } \\
\text { Raffo, Protalix, Tuteur y Alexion }\end{array}$ \\
\hline Orlando Olivares & Congreso SLANH 2021, conferencia sobre enfermedad de Fabry \\
\hline José Gabriel López & Ninguno \\
\hline Gustavo María Ferrari & Sanofi: actividad educativa \\
\hline Javier Ibarra & Ha recibido honorarios de Genzyme y Takeda \\
\hline
\end{tabular}




\section{Referencias}

[1] Ortiz A, Kanters S, Hamed A, DasMahapatra P, Poggio E, Maski M, et al. Agalsidase beta treatment slows estimated glomerular filtration rate loss in classic Fabry disease patients: results from an individual patient data meta-analysis. Clin Kidney J. 2020;1-11. DOI: https: //doi.org/10.1093/ckj/sfaa065 个Ver página 5, 11

[2] Aratani S, Yamakawa H, Suzuki S, Otsuka T, Sakai Y, Shimizu A, et al. A case of female Fabry disease revealed by renal biopsy. CEN Case Rep. 2020;9(1):24-9. DOI: https://oi.org/ 10.1007/s13730-019-00420-5 个Ver página 5, 11

[3] Jaurretche S, Perez GR, Venera G. High Lyso-Gb3 Plasma Levels Associated with Decreased miR-29 and miR-200 Urinary Excretion in Young Non-Albuminuric Male Patient with Classic Fabry Disease. Case Rep Nephrol. 2019:4980942. DOI: https://oi.org/10.1155/2019/ $4980942 \uparrow$ Ver página 5, 11, 23

[4] Germain DP, Elliott PM, Falissard B, Fomin VV, Hilz MJ, Jovanovic A, et al. The effect of enzyme replacement therapy on clinical outcomes in male patients with Fabry disease: A systematic literature review by a European panel of experts. Mol Genet Metab reports. 2019 jun.;19:100454. DOI: https://doi.org/10.1016/j.ymgmr.2019.100454 个Ver página 5, 11

[5] Riccio E, Sabbatini M, Capuano I, Pisani A. Early Biomarkers of Fabry Nephropathy: A Review of the Literature. Nephron. 2019;143(4):274-81. DOI: https://doi.org/10.1159/000502907 个Ver página $5,10,11$

[6] Roggero L, Auricchio S, Pieruzzi F. La terapia enzimatica sostitutiva nella malattia di Fabry. G di Tec Nefrol Dial. 2019;31(3):197-200. DOI: https://doi.org/10.33393/gcnd.2019.528 个Ver página 5,11

[7] van der Tol L, Svarstad E, Ortiz A, Tøndel C, Oliveira JP, Vogt L, et al. Chronic kidney disease and an uncertain diagnosis of Fabry disease: Approach to a correct diagnosis. Mol Genet

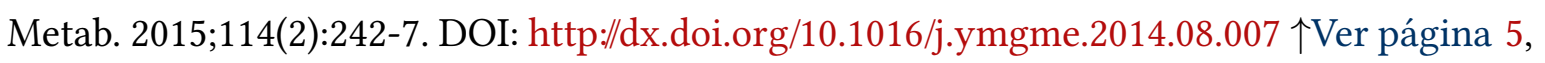
14

[8] García-Trabanino R, Badilla-Porras R, Carazo K, Courville K, de Luna E, Lemus P, et al. Consenso del Grupo Centroamericano y del Caribe para el Estudio y Tratamiento de la Enfermedad de Fabry. 2017;4(1):27-38. DOI: https:/doi.org/10.1016/j.nefrol.2016.11.003 $\uparrow$ Ver página $5,12,13,14,17,18,19,23,25,27,35$

[9] Terryn W, Cochat P, Froissart R, Ortiz A, Pirson Y, Poppe B, et al. Fabry nephropathy: indications for screening and guidance for diagnosis and treatment by the European Renal 
Best Practice. Nephrol Dial Transplant. 2013 mzo.;28(3):505-17. DOI: https:/doi.org/10.1093/ ndt/gfs526 个Ver página 5, 14, 15, 16, 17, 18, 19, 23, 25, 27

[10] Spada M, Pagliardini S, Yasuda M, Tukel T, Thiagarajan G, Sakuraba H, et al. High incidence of later-onset fabry disease revealed by newborn screening. Am J Hum Genet. 2006 jul.;79(1):31-40. DOI: https:/doi.org/10.1086/504601 个Ver página 5, 15

[11] Turkmen K, Baloglu I. Fabry disease: where are we now? Int Urol Nephrol. 2020 jul.;52(11):2113-22. DOI: https:/doi.org/10.1007/s11255-020-02546-3 个Ver página 5, 10, 12, $13,15,16,19,25$

[12] Colpart P, Félix S. Fabry Nephropathy. Arch Pathol Lab Med. 2017 ag.;141(8):1127-31. DOI: https://doi.org/10.5858/arpa.2016-0418-RS 个Ver página 5, 10, 12, 13, 14, 19, 23

[13] Ortiz A, Germain DP, Desnick RJ, Politei J, Mauer M, Burlina A, et al. Fabry disease revisited: Management and treatment recommendations for adult patients. Mol Genet Metab. 2018 abr.;123(4):416-27. DOI: https://doi.org/10.1016/j.ymgme.2018.02.014 个Ver página 5, 12, 14,32

[14] Wanner C, Arad M, Baron R, Burlina A, Elliott PM, Feldt-Rasmussen U, et al. European expert consensus statement on therapeutic goals in Fabry disease. Mol Genet Metab. 2018;124(3):189-203. DOI: https:/doi.org/10.1016/j.ymgme.2018.06.004 个Ver página 5

[15] Calderón-Sandubete EJ, Briones-Pérez E, Alonso-Ortiz C, Santamaría-Olmo R, LópezMendoza M, Barcos-Martínez M, et al. Guía de práctica clínica multidisciplinar española sobre la enfermedad de Anderson-Fabry en adultos. I: Método y recomendaciones. Rev Clin Esp. 2019;219(4):200-7. DOI: https://doi.org/10.1016/j.rce.2018.09.017 个Ver página 5

[16] Germain DP. Fabry disease. Orphanet J Rare Dis. 2010 nov.;5:30. DOI: https:/doi.org/10. 1186/1750-1172-5-30 个Ver página 5, 15

[17] Instituto Nacional de Salud (INS). Boletín Epidemiológico Semanal. Semana epidemiológica 0714 al 20 de febrero de 2021. 2021. Disponible en: https:/www.ins.gov.co/ buscador-eventos/BoletinEpidemiologico/2021_Boletin_epidemiologico_semana_7.pdf $\uparrow$ Ver página 5,15

[18] Congreso de Colombia. Ley 1438 de 2011 [Internet]. 2011. Disponible en: https:/ colaboracion.dnp.gov.co/CDT/Normatividad/ley1438de2011.pdf $\uparrow$ Ver página 5

[19] Ministerio de Salud y Protección Social de Colombia (MinSalud). Colombia asume el reto de la atención integral para enfermedades huérfanas [Internet]. 2021. Disponible en: https:/www.minsalud.gov.co/Paginas/ 
Colombia-asume-el-reto-de-la-atencion-integral-para-enfermedades-huerfanas.aspx 个Ver página 5

[20] Sanabria AJ, Rigau D, Rotaeche R, Selva A, Marzo-Castillejo M, Alonso-Coello P. Sistema GRADE: metodología para la realización de recomendaciones para la práctica clínica. Aten-

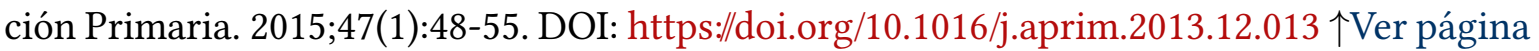
10

[21] Parini R, Pintos-Morell G, Hennermann JB, Hsu TR, Karabul N, Kalampoki V, et al. Analysis of Renal and Cardiac Outcomes in Male Participants in the Fabry Outcome Survey Starting Agalsidase Alfa Enzyme Replacement Therapy Before and After 18 Years of Age. Drug Des Devel Ther. 2020;14:2149-58. DOI: https:/doi.org/10.2147/DDDT.S249433 $\uparrow$ Ver página 10,12

[22] Passaglia B, Demarchi R, Kirsztajn GM. Fabry disease: genetics, pathology, and treatment. Rev Assoc Med Bras. 2020 en.;66(supl. 1):s10-6. DOI: https://doi.org/10.1590/1806-9282.66.s1. $10 \uparrow$ Ver página 10,12

[23] Jaurretche S, Antongiovanni N, Perretta F. Fabry nephropathy. Role of nephrologist and clinical variables associated with the diagnosis. Nefrología. 2019;39(3):294-300. DOI: https: //doi.org/10.1016/j.nefro.2018.10.017 $\uparrow$ Ver página 10, 11, 17

[24] Sasa H, Nagao M, Kino K. Safety and effectiveness of enzyme replacement therapy with agalsidase alfa in patients with Fabry disease: Post-marketing surveillance in Japan. Mol Genet Metab. 2019 abr.;126(4):448-59. DOI: https:/doi.org/10.1016/j.ymgme.2019.02.005 个Ver página 10

[25] Braga MC, Fonseca FL, Marins MM, Gomes CP, Bacci MR, Martins AM, et al. Evaluation of Beta 2-Microglobulin, Cystatin C, and Lipocalin-2 as Renal Biomarkers for Patients with Fabry Disease. Nephron. 2019;143(4):217-27. DOI: https://doi.org/10.1159/000500570 个Ver página 10

[26] Lenders M, Neußer LP, Rudnicki M, Nordbeck P, Canaan-Kühl S, Nowak A, et al. DoseDependent Effect of Enzyme Replacement Therapy on Neutralizing Antidrug Antibody Titers and Clinical Outcome in Patients with Fabry Disease. J Am Soc Nephrol. 2018 dic.;29(12):2879-89. DOI: https:/doi.org/10.1681/ASN.2018070740 个Ver página 10, 33

[27] Auray-Blais C, Lavoie P, Abaoui M, Côté AM, Boutin M, Akbari A, et al. High-risk screening for Fabry disease in a Canadian cohort of chronic kidney disease patients. Clin Chim Acta. 2020;501:234-40. DOI: https://oi.org/10.1016/j.cca.2019.10.045 $\uparrow$ Ver página 10 
[28] Trimarchi H, Canzonieri R, Schiel A, Politei J, Costales-Collaguazo C, Stern A, et al. Expression of uPAR in Urinary Podocytes of Patients with Fabry Disease. Int J Nephrol. 2017;2017:1287289. DOI: https://doi.org/10.1155/2017/1287289 个Ver página 10

[29] Rozenfeld PA, de Los Angeles-Bolla M, Quieto P, Pisani A, Feriozzi S, Neuman P, et al. Pathogenesis of Fabry nephropathy: The pathways leading to fibrosis. Mol Genet Metab. 2020 febr.;129(2):132-41. DOI: https:/doi.org/10.1016/j.ymgme.2019.10.010 个Ver página 10, $11,23,25$

[30] Zhang R, Chen Z, Lang Y, Shao S, Cai Y, You Q, et al. Sudden onset of nephrotic syndrome in an asymptomatic Fabry patient: a case report. Ren Fail. 2020;42(1):958-65. DOI: https:/ doi.org/10.1080/0886022X.2020.1818578 个Ver página 10, 13

[31] Schiffmann R. Fabry disease. 1.a ed. Texas, Estados Unidos: Elsevier B.V.; 2015. DOI: http: //dx.doi.org/10.1016/B978-0-444-62702-5.00017-2 个Ver página 10

[32] Hopkin RJ, Cabrera G, Charrow J, Lemay R, Martins AM, Mauer M, et al. Risk factors for severe clinical events in male and female patients with Fabry disease treated with agalsidase beta enzyme replacement therapy: Data from the Fabry Registry. Mol Genet Metab. 2016 sept.;119(1-2):151-9. DOI: https:/doi.org/10.1016/j.ymgme.2016.06.007 个Ver página 10, 25

[33] Yeniçerioğlu Y, Akdam H, Dursun B, Alp A, Eyiler FS, Akın D, et al. Screening Fabry’s disease in chronic kidney disease patients not on dialysis: A multicenter study. Ren Fail. 2017;39(1):104-11. DOI: https:/doi.org/10.1080/0886022X.2016.1254656 个Ver página 11, 14, 17

[34] Aguiar P, Azevedo O, Pinto R, Marino J, Baker R, Cardoso C, et al. New biomarkers defining a novel early stage of Fabry nephropathy: A diagnostic test study. Mol Genet Metab. 2017 jun.;121(2):162-9. DOI: https://doi.org/10.1016/j.ymgme.2017.05.007 $\uparrow$ Ver página 11

[35] İnan R, Meşe $M$, Bicik Z. Multidisciplinary approach to Fabry disease: from the eye of a neurologist. Acta Neurol Belg. 2020;120(6):1333-9. DOI: https:/doi.org/10.1007/ s13760-019-01138-y $\uparrow V e r$ página 11, 12, 15

[36] Madsen CV, Granqvist H, Petersen JH, Rasmussen ÅK, Lund AM, Oturai P, et al. Agerelated renal function decline in Fabry disease patients on enzyme replacement therapy: a longitudinal cohort study. Nephrol Dial Transplant. 2019 sept.;34(9):1525-33. DOI: https:/ doi.org/10.1093/ndt/gfy357 个Ver página 11, 12, 13, 17, 24, 25, 27, 36

[37] Jaurretche SP, Antongiovanni N, Perretta F. Direct correlation between age at diagnosis and severity of nephropathy in fabry disease patients. Indian J Nephrol. 2010;8719(2006):398-401. DOI: https:/doi.org/10.4103/ijn.IJN_167_18 个Ver página 11 
[38] Lepedda AJ, Fancellu L, Zinellu E, De Muro P, Nieddu G, Deiana GA, et al. Urine bikunin as a marker of renal impairment in Fabry's disease. Biomed Res Int. 2013;2013. DOI: https:/ doi.org/10.1155/2013/205948 个Ver página 11

[39] Rozenfeld P, Feriozzi S. Contribution of inflammatory pathways to Fabry disease pathogenesis. Mol Genet Metab. 2017 nov.;122(3):19-27. DOI: https:/doi.org/10.1016/j.ymgme. 2017.09.004 个Ver página 11, 12, 13

[40] Ortiz A, Abiose A, Bichet DG, Cabrera G, Charrow J, Germain DP, et al. Time to treatment benefit for adult patients with Fabry disease receiving agalsidase $\beta$ : data from the Fabry Registry. J Med Genet. 2016 jul.;53(7):495-502. DOI: https://doi.org/10.1136/ jmedgenet-2015-103486 个Ver página 11

[41] Riccio E, Sabbatini M, Bruzzese D, Annicchiarico-Petruzzelli L, Pellegrino A, Spinelli L, et al. Glomerular Hyperfiltration: An Early Marker of Nephropathy in Fabry Disease. Nephron. 2019;141(1):10-7. DOI: https:/doi.org/10.1159/000493469 ^Ver página 11

[42] Fall B, Scott CR, Mauer M, Shankland S, Pippin J, Jefferson JA, et al. Urinary Podocyte Loss Is Increased in Patients with Fabry Disease and Correlates with Clinical Severity of Fabry Nephropathy. PLoS One. 2016;11(12):e0168346. DOI: https:/doi.org/10.1371/journal. pone.0168346 个Ver página 11

[43] Becherucci F, Romagnani P. When foots come first: Early signs of podocyte injury in fabry nephropathy without proteinuria. Nephron. 2015;129(1):3-5. DOI: https:/doi.org/10. 1159/000369307 个Ver página 11, 13

[44] Skrunes R, Svarstad E, Kampevold-Larsen K, Leh S, Tøndel C. Reaccumulation of globotriaosylceramide in podocytes after agalsidase dose reduction in young Fabry patients. Nephrol Dial Trans. 2017 my.;32(5):807-13. DOI: https://doi.org/10.1093/ndt/gfw094 个Ver página $11,24,31,34,35$

[45] Wanner C, Arad M, Baron R, Burlina A, Elliott PM, Feldt-Rasmussen U, et al. European expert consensus statement on therapeutic goals in Fabry disease. Mol Genet Metab. 2018 jul.;124(3):189-203. DOI: https://doi.org/10.1016/j.ymgme.2018.06.004 个Ver página 11

[46] Vujkovac B. Fabry disease: diagnostic methods in nephrology practice. Clin Nephrol. 2017;88(13):44-7. DOI: https:/doi.org/10.5414/CNP88FX28 个Ver página 12

[47] Kaminsky P, Noel E, Jaussaud R, Leguy-Seguin V, Hachulla E, Zenone T, et al. Multidimensional analysis of clinical symptoms in patients with Fabry's disease. Int J Clin Pract. 2013;67(2):120-7. DOI: https:/doi.org/10.1111/ijcp.12016 个Ver página 12, 13 
[48] Martins AM, D’Almeida V, Kyosen SO, Takata ET, Delgado AG, Gonçalves AM, et al. Guidelines to diagnosis and monitoring of Fabry disease and review of treatment experiences. J Pediatr. 2009 oct.;155(supl. 4):S19-31. DOI: https:/doi.org/10.1016/j.jpeds.2009.07.003 个Ver página $12,13,15,16,17$

[49] Politei J, Aiziczon D, Aguilar MA, Alonso S, Amoreo O, Andrade LA, et al. Recomendaciones para el diagnóstico, tratamiento y seguimiento de la enfermedad de Fabry en Argentina. Rev Nefrol Argent. 2018;16(2):1-29. Disponible en: http:/www.nefrohospbritanico.org.ar/

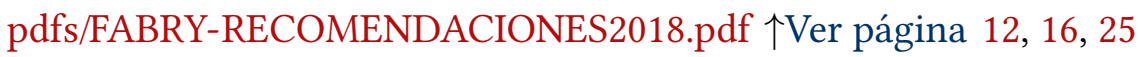

[50] Trimarchi H, Forrester M, Lombi F, Pomeranz V, Raña MS, Karl A, et al. Amiloride as an Alternate Adjuvant Antiproteinuric Agent in Fabry Disease: The Potential Roles of Plasmin and uPAR. Case Rep Nephrol. 2014;2014:854521. DOI: https://doi.org/10.1155/2014/854521 个Ver página 13

[51] Valbuena C, Carvalho E, Bustorff M, Ganhão M, Relvas S, Nogueira R, et al. Kidney biopsy findings in heterozygous Fabry disease females with early nephropathy. Virchows Arch. 2008;453(4):329-38. DOI: https://doi.org/10.1007/s00428-008-0653-2 个Ver página 13, 23

[52] Waldek S, Feriozzi S. Fabry nephropathy: a review - how can we optimize the management of Fabry nephropathy? BMC Nephrol. 2014 my.;15:72. DOI: https://doi.org/10.1186/ 1471-2369-15-72 $\uparrow$ Ver página 13, 19, 23, 24, 25, 27, 32, 35

[53] Barbey F, Lidove O, Schwarting A. Fabry nephropathy: 5 years of enzyme replacement therapy-a short review. NDT plus. 2008;1:11-9. DOI: https:/doi.org/10.1093/ndtplus/sfm022 $\uparrow$ Ver página 13, 16, 19

[54] Ries M, Bove-Bettis KE, Choyke P, Kopp JB, Austin HA, Brady RO, et al. Parapelvic kidney cysts: A distinguishing feature with high prevalence in Fabry disease. Kidney Int. 2004;66(3):978-82. DOI: https://doi.org/10.1111/j.1523-1755.2004.00846.x 个Ver página 14

[55] Orphannet. The portal for rare diseases and orphan drugs [Internet]. Fabry disease. 2021. Disponible en: https:/www.orpha.net/consor/cgi-bin/OC Exp.php?Expert=324\&lng= EN $\uparrow$ Ver página 14

[56] Turkmen K, Guclu A, Sahin G, Kocyigit I, Demirtas L, Erdur FM, et al. The Prevalence of Fabry Disease in Patients with Chronic Kidney Disease in Turkey: The TURKFAB Study. Kidney Blood Press Res. 2016;41(6):1016-24. DOI: https:/doi.org/10.1159/000452605 个Ver página 14

[57] Battaglia Y, Fiorini F, Azzini C, Esposito P, De Vito A, Granata A, et al. Deficiency in the Screening Process of Fabry Disease: Analysis of Chronic Kidney Patients Not on Dialysis. Front Med. 2021;8:640876. DOI: https:/doi.org/10.3389/fmed.2021.640876 个Ver página 15 
[58] Beirão I, Cabrita A, Torres M, Silva F, Aguiar P, Laranjeira F, et al. Biomarkers and Imaging Findings of Anderson-Fabry Disease-What We Know Now. Dis. 2017 jun.;5(2):15. DOI: https: //doi.org/10.3390/diseases5020015 个Ver página 15

[59] Sirrs S, Bichet D, Iwanochko M, Khan A, Moore D, West M. Canadian Fabry Disease Treatment Guidelines 2018. 2019. Disponible en: https:/garrod.ca/wp-content/uploads/2020/ 02/Canadian-Fabry-Treatment-Guidelines-2019-final.pdf $\uparrow$ Ver página 15, 25, 26

[60] Langeveld M, Hollak CE, Veen S, Eskes E. Protocol Diagnosis, evaluation and treatment of Fabry disease in the Netherlands. Amsterdam: UMC; 2020. $\uparrow$ Ver página 15, 24, 27

[61] Gal A, Hughes DA, Winchester B. Toward a consensus in the laboratory diagnostics of Fabry disease - recommendations of a European expert group. J Inherit Metab Dis. 2011 abr.;34(2):509-14. DOI: https://doi.org/10.1007/s10545-010-9261-9 $\uparrow$ Ver página 16

[62] Sánchez-Niño MD, Perez-Gomez MV, Valiño-Rivas L, Torra R, Ortiz A. Podocyturia: why it may have added value in rare diseases. Clin Kidney J. 2019 febr.;12(1):49-52. DOI: https:/ doi.org/10.1093/ckj/sfy081 个Ver página 16, 17, 19

[63] Warnock DG, Daina E, Remuzzi G, West M. Enzyme replacement therapy and Fabry nephropathy. Clin J Am Soc Nephrol. 2010 febr.;5(2):371-8. DOI: https://doi.org/10.2215/ CJN.06900909 $\uparrow$ Ver página 17, 27

[64] Mauer M, Glynn E, Svarstad E, Tøndel C, Gubler MC, West M, et al. Mosaicism of podocyte involvement is related to podocyte injury in females with Fabry disease. PLoS One. 2014;9(11):e112188. DOI: https://doi.org/10.1371/journal.pone.0112188 个Ver página 17

[65] Pereira EM, Silva AS, Labilloy A, Monte-Neto JT, Monte SJ. Podocyturia in Fabry disease. J Bras Nefrol. 2016;38(1):49-53. DOI: https:/doi.org/10.5935/0101-2800.20160008 个Ver página 17,24

[66] Smid BE, van der Tol L, Cecchi F, Elliott PM, Hughes DA, Linthorst GE, et al. Uncertain diagnosis of Fabry disease: consensus recommendation on diagnosis in adults with left ventricular hypertrophy and genetic variants of unknown significance. Int J Cardiol. 2014 dic.;177(2):400-8. DOI: https://doi.org/10.1016/j.ijcard.2014.09.001 个Ver página 19

[67] Costa RM, Martul EV, Reboredo JM, Cigarrán S. Curvilinear bodies in hydroxychloroquine-induced renal phospholipidosis resembling Fabry disease. Clin Kidney J. 2013 oct.;6(5):533-6. DOI: https://doi.org/10.1093/ckj/sft089 个Ver página 23

[68] Weidemann F, Niemann M, Störk S, Breunig F, Beer M, Sommer C, et al. Long-term outcome of enzyme-replacement therapy in advanced Fabry disease: evidence for disea- 
se progression towards serious complications. J Intern Med. 2013 oct.;274(4):331-41. DOI: https://doi.org/10.1111/joim.12077 个Ver página 24, 27

[69] Mignani R, Pieroni M, Pisani A, Spada M, Battaglia Y, Verrecchia E, et al. New insights from the application of the FAbry STabilization indEX in a large population of Fabry cases. Clin Kidney J. 2019 febr. 1;12(1):65-70. DOI: https://oi.org/10.1093/ckj/sfy108 个Ver página 24

[70] Iwafuchi Y, Maruyama H, Morioka T, Noda S, Nagata H, Oyama Y, et al. Enzyme replacement therapy in a patient of heterozygous Fabry disease: clinical and pathological evaluations by repeat kidney biopsy and a successful pregnancy. CEN Case Rep. 2017;6(2):210-4. DOI: http:/dx.doi.org/10.1007/s13730-017-0277-y 个Ver página 25, 35

[71] Riccio E, Zanfardino M, Ferreri L, Santoro C, Cocozza S, Capuano I, et al. Switch from enzyme replacement therapy to oral chaperone migalastat for treating fabry disease: reallife data. Eur J Hum Genet. 2020 jul.;1662-8. DOI: https:/doi.org/10.1038/s41431-020-0677-x $\uparrow$ Ver página 28

[72] Germain DP, Hughes DA, Nicholls K, Bichet DG, Giugliani R, Wilcox WR, et al. Treatment of Fabry's Disease with the Pharmacologic Chaperone Migalastat. N Engl J Med. 2016;375(6):545-55. DOI: https://oi.org/10.1056/NEJMoa1510198 个Ver página 28

[73] Müntze J, Gensler D, Maniuc O, Liu D, Cairns T, Oder D, et al. Oral Chaperone Therapy Migalastat for Treating Fabry Disease: Enzymatic Response and Serum Biomarker Changes After 1 Year. Clin Pharmacol Ther. 2019 my.;105(5):1224-33. DOI: https:/doi.org/10.1002/cpt. $1321 \uparrow$ Ver página 29

[74] Hughes DA, Nicholls K, Shankar SP, Sunder-Plassmann G, Koeller D, Nedd K, et al. Oral pharmacological chaperone migalastat compared with enzyme replacement therapy in Fabry disease: 18-month results from the randomised phase III ATTRACT study. J Med

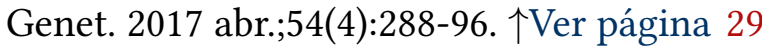

[75] El Dib R, Gomaa H, Carvalho RP, Camargo SE, Bazan R, Barretti P, et al. Enzyme replacement therapy for Anderson-Fabry disease. Cochrane Database Syst Rev. 2016;2016(7). DOI: https://doi.org/10.1002/14651858.CD006663.pub4 个Ver página 30

[76] Sirrs SM, Bichet DG, Casey R, Clarke JT, Lemoine K, Doucette S, et al. Outcomes of patients treated through the Canadian Fabry disease initiative. Mol Genet Metab. 2014 abr.;111(4):499-506. DOI: https://doi.org/10.1016/j.ymgme.2014.01.014 个Ver página 30

[77] Arends M, Biegstraaten M, Wanner C, Sirrs S, Mehta A, Elliott PM, et al. Agalsidase alfa versus agalsidase beta for the treatment of Fabry disease: an international cohort study. J 
Med Genet. 2018 my.;55(5):351-8. DOI: https://doi.org/10.1136/jmedgenet-2017-104863 个Ver página 31,33

[78] Najafian B, Tøndel C, Svarstad E, Sokolovkiy A, Smith K, Mauer M. One Year of Enzyme Replacement Therapy Reduces Globotriaosylceramide Inclusions in Podocytes in Male Adult Patients with Fabry Disease. PLoS One. 2016;11(4):e0152812. DOI: https://doi.org/ 10.1371/journal.pone.0152812 个Ver página 31

[79] Skrunes R, Tøndel C, Leh S, Larsen KK, Houge G, Davidsen ES, et al. Long-Term DoseDependent Agalsidase Effects on Kidney Histology in Fabry Disease. Clin J Am Soc Nephrol. 2017 sept.;12(9):1470-9. DOI: https://doi.org/10.2215/CJN.01820217 ^Ver página 31

[80] Najafian B, Tøndel C, Svarstad E, Gubler MC, Oliveira JP, Mauer M. Accumulation of Globotriaosylceramide in Podocytes in Fabry Nephropathy Is Associated with Progressive Podocyte Loss. J Am Soc Nephrol. 2020 abr.;31(4):865-75. DOI: https://doi.org/10.1681/ASN. $2019050497 \uparrow$ Ver página 31

[81] Lenders M, Canaan-Kühl S, Krämer J, Duning T, Reiermann S, Sommer C, et al. Patients with Fabry Disease after Enzyme Replacement Therapy Dose Reduction and Switch2-Year Follow-Up. J Am Soc Nephrol. 2016 mzo.;27(3):952-62. DOI: https://doi.org/10.1681/ ASN.2015030337 $\uparrow$ Ver página 31

[82] Lenders M, Nordbeck P, Canaan-Kühl S, Kreul L, Duning T, Lorenz L, et al. Treatment switch in Fabry disease- a matter of dose? J Med Genet. 2021;58:342-50. DOI: https://doi.org/ 10.1136/jmedgenet-2020-106874 个Ver página 32

[83] Lenders M, Brand E. Effects of Enzyme Replacement Therapy and Antidrug Antibodies in Patients with Fabry Disease. J Am Soc Nephrol. 2018 sept.;29(9):2265-78. DOI: https:/ doi.org/10.1681/ASN.2018030329 个Ver página 32, 35

[84] Krämer J, Lenders M, Canaan-Kühl S, Nordbeck P, Üçeyler N, Blaschke D, et al. Fabry disease under enzyme replacement therapy-new insights in efficacy of different dosages. Nephrol Dial Trans. 2018 ag.;33(8):1362-72. DOI: https://doi.org/10.1093/ndt/gfx319 个Ver página 34

[85] Ripeau D, Amartino H, Cedrolla M, Urtiaga L, Urdaneta B, Cano M, et al. Switch from agalsidase beta to agalsidase alfa in the enzyme replacement therapy of patients with fabry disease in latin America. Med. 2017;77(3):173-9. 个Ver página 34

[86] Lin HY, Huang YH, Liao HC, Liu HC, Hsu TR, Shen CI, et al. Clinical observations on enzyme replacement therapy in patients with Fabry disease and the switch from agalsidase beta to agalsidase alfa. J Chin Med Assoc. 2014 abr.;7(4):190-7. DOI: https://doi.org/10.1016/ j.jcma.2013.11.006 $\uparrow$ Ver página 34 
[87] Tsuboi K, Yamamoto H. Clinical observation of patients with Fabry disease after switching from agalsidase beta (Fabrazyme) to agalsidase alfa (Replagal). Genet Med. 2012 sept.;14(9):779-86. DOI: https://doi.org/10.1038/gim.2012.39 个Ver página 34

[88] Bichet DG, Aerts JM, Auray-Blais C, Maruyama H, Mehta AB, Skuban N, et al. Assessment of plasma lyso-Gb3 for clinical monitoring of treatment response in migalastat-treated patients with Fabry disease. Genet Med. 2021;23(1):192-201. DOI: https:/doi.org/10.1038/ s41436-020-00968-z $\uparrow V e r$ página 36 


\section{Anexos}

\section{Anexo A. Preguntas clínicas desarrolladas}

\section{Definición}

1. ¿Qué es la enfermedad de Fabry?

2. ¿Cuál es la fisiopatología?

3. ¿Cuáles son las manifestaciones clínicas generales?

4. ¿Cómo se manifiesta la enfermedad a nivel renal?

5. ¿Cuál es el perfil epidemiológico de la enfermedad?

\section{Diagnóstico}

1. ¿Cómo se diagnostica la enfermedad de Fabry?

2. ¿Cómo se diagnostica el compromiso renal por enfermedad de Fabry?

3. ¿Cuáles son los exámenes de apoyo para un paciente con sospecha de enfermedad de Fabry?

4. ¿Cuándo indicar la biopsia renal?

5. ¿Cuáles son los hallazgos histopatológicos en la biopsia renal?

6. ¿Cuáles enfermedades glomerulares y tubulares son diagnóstico diferencial de enfermedad de Fabry?

\section{Tratamiento}

1. ¿Cómo evaluar la respuesta al tratamiento de terapias de reemplazo enzimático en enfermedad de Fabry?

2. ¿Cuáles son los criterios desde el punto de vista renal para iniciar tratamiento de reemplazo enzimático?

3. ¿Existen otros tratamientos para evitar la progresión renal?

4. ¿Cuál es la indicación de chaperonas en enfermedad de Fabry?

5. ¿Existe diferencia entre las terapias de reemplazo enzimático en resultados renales? 
6. ¿Cuál es el impacto clínico de los anticuerpos contra la terapia enzimática?

7. ¿Cuándo está indicado el cambio de terapia?

8. ¿Cuál es el valor del lyso-Gb3 en enfermedad de Fabry?

9. ¿Cuál es la interpretación del lyso-Gb3 en el diagnóstico y seguimiento de enfermedad de Fabry? 


\section{Anexo B. Estrategias de búsqueda}

\begin{tabular}{|c|c|}
\hline $\begin{array}{c}\text { Fuente } \\
\text { consultada }\end{array}$ & Estrategia de búsqueda \\
\hline Pubmed & $\begin{array}{l}\text { ("fabry disease"[Title/Abstract] OR "fabry s disease"[Title/Abstract] } \\
\text { OR ("lysosomal storage diseases"[MeSH Terms] OR ("lysosomal"[All Fields] } \\
\text { AND "storage"[All Fields] AND "diseases"[All Fields]) OR "lysosomal storage } \\
\text { diseases"[All Fields] OR ("lysosomal"[All Fields] AND "storage"[All Fields] } \\
\text { AND "Disease"[All Fields]) OR "lysosomal storage disease"[All Fields] } \\
\text { OR (.alpha galactosidase"[MeSH Terms] OR .alpha galactosidase"[All Fields] } \\
\text { OR (.alpha"[All Fields] AND "galactosidase"[All Fields]) OR .alpha galactosidase" } \\
\text { [All Fields]))) AND (renal failure"[Title/Abstract] OR "kidney failure"[Title/Abstract] } \\
\text { OR "kidney disease"[Title/Abstract] OR renal variant"[Title/Abstract] } \\
\text { OR "nephropathy"[Title/Abstract] OR "proteinuria"[Title/Abstract]) }\end{array}$ \\
\hline Embase & $\begin{array}{l}\text { \#9 \#6 AND \#7 AND \#8 } \\
\text { \#8 \#4 OR \#5 } \\
\text { \#7 \#1 OR \#2 OR \#3 } \\
\text { \#6 adult:ab,ti } \\
\text { \#5 'kidney disease':ab,ti } \\
\text { \#4 'kidney failure':ab,ti } \\
\text { \#3 'alpha galactosidase':ab,ti } \\
\text { \#2 'fabry disease':ab,ti } \\
\text { \#1 'lysosomal storage diseases':ab,ti }\end{array}$ \\
\hline $\begin{array}{l}\text { Google } \\
\text { Scholar }\end{array}$ & fabry disease AND renal variant \\
\hline
\end{tabular}




\section{Anexo C. Evaluación de calidad}

\begin{tabular}{|c|c|c|}
\hline Documento & Tipo de documento & $\begin{array}{c}\text { Calidad de evidencia - } \\
\text { Riesgo de sesgo }\end{array}$ \\
\hline $\begin{array}{l}\text { Aguiar P, Azevedo O, Pinto R, Marino J, Baker R, Cardoso C, et al. } \\
\text { New biomarkers defining a novel early } \\
\text { stage of Fabry nephropathy: A diagnostic } \\
\text { test study. }\end{array}$ & Prueba diagnóstica & No cumple \\
\hline $\begin{array}{l}\text { Aratani S, Yamakawa H, Suzuki S, Otsuka T, Sakai Y, } \\
\text { Shimizu A, et al. } \\
\text { A case of female Fabry disease revealed } \\
\text { by renal biopsy. }\end{array}$ & Reporte de caso & Cumple reporte JBI \\
\hline $\begin{array}{l}\text { Arends M, Biegstraaten M, Wanner C, Sirrs S, Mehta A, } \\
\text { Elliott PM, et al. } \\
\text { Agalsidase alfa versus agalsidase beta for } \\
\text { the treatment of Fabry disease: an } \\
\text { international cohort study. }\end{array}$ & Cohorte & Cumple reporte JBI \\
\hline $\begin{array}{l}\text { Auray-Blais C, Lavoie P, Abaoui M, Côté AM, Boutin M, } \\
\text { Akbari A, et al. } \\
\text { High-risk screening for Fabry disease } \\
\text { in a Canadian cohort of chronic kidney disease } \\
\text { patients. }\end{array}$ & $\begin{array}{l}\text { Cohorte de pacientes } \\
\text { (Serie de casos) }\end{array}$ & Cumple reporte JBI \\
\hline $\begin{array}{l}\text { Barbey F, Lidove O, Schwarting A. } \\
\text { Fabry nephropathy: } 5 \text { years of enzyme replacement } \\
\text { therapy-a short review. }\end{array}$ & Revisión narrativa & $\mathrm{N} / \mathrm{A}$ \\
\hline $\begin{array}{l}\text { Battaglia Y, Fiorini F, Azzini C, Esposito P, De Vito A, } \\
\text { Granata A, et al. } \\
\text { Deficiency in the Screening Process of Fabry } \\
\text { Disease: Analysis of Chronic Kidney Patients } \\
\text { Not on Dialysis. }\end{array}$ & Revisión narrativa & $\mathrm{N} / \mathrm{A}$ \\
\hline $\begin{array}{l}\text { Becherucci F, Romagnani P. } \\
\text { When foots come first: Early signs of podocyte } \\
\text { injury in fabry nephropathy without proteinuria. }\end{array}$ & Editorial & $\mathrm{N} / \mathrm{A}$ \\
\hline $\begin{array}{l}\text { Beirão I, Cabrita A, Torres M, Silva F, Aguiar P, Laranjeira F, } \\
\text { et al. } \\
\text { Biomarkers and Imaging Findings of } \\
\text { Anderson-Fabry Disease-What WeKnow Now. }\end{array}$ & Revisión narrativa & $\mathrm{N} / \mathrm{A}$ \\
\hline $\begin{array}{l}\text { Bichet DG, Aerts JM, Auray-Blais C, Maruyama H, Mehta AB, } \\
\text { Skuban N, et al. } \\
\text { Assessment of plasma lyso-Gb3 for clinical } \\
\text { monitoring of treatment response in } \\
\text { migalastat-treated patients with Fabry disease. }\end{array}$ & Análisis post hoc & $\mathrm{N} / \mathrm{A}$ \\
\hline
\end{tabular}




\begin{tabular}{|c|c|c|}
\hline Documento & Tipo de documento & $\begin{array}{l}\text { Calidad de evidencia - } \\
\text { Riesgo de sesgo }\end{array}$ \\
\hline $\begin{array}{l}\text { Braga MC, Fonseca FL, Marins MM, Gomes CP, Bacci MR, } \\
\text { Martins AM, et al. } \\
\text { Evaluation of Beta 2- Microglobulin, Cystatin C, } \\
\text { and Lipocalin-2 as Renal Biomarkers for Patients } \\
\text { with Fabry Disease. }\end{array}$ & $\begin{array}{l}\text { Corte transversal } \\
\text { analítico }\end{array}$ & $\begin{array}{l}\text { No cumple reporte en JBI. } \\
\text { No es clara la medición } \\
\text { de exposición y el análisis } \\
\text { realizado. }\end{array}$ \\
\hline $\begin{array}{l}\text { Calderón-Sandubete EJ, Briones-Pérez E, Santamaría-Olmo R, } \\
\text { López-Mendoza M, Barcos-Martínez M, et al. } \\
\text { Guía de práctica clínica multidisciplinar española } \\
\text { sobre la enfermedad de Anderson-Fabry en adultos. } \\
\text { I: Método y recomendaciones. }\end{array}$ & GPC & \\
\hline $\begin{array}{l}\text { Colpart P, Félix S. } \\
\text { Fabry Nephropathy. }\end{array}$ & Revisión narrativa & $\mathrm{N} / \mathrm{A}$ \\
\hline $\begin{array}{l}\text { Congreso de Colombia. } \\
\text { Ley } 1438 \text { de } 2011 .\end{array}$ & Normativa & N/A \\
\hline $\begin{array}{l}\text { Costa RM, Martul E V, Reboredo JM, Cigarrán S. } \\
\text { Curvilinear bodies in hydroxychloroquine } \\
\text {-induced renal phospholipidosis resembling Fabry } \\
\text { disease. }\end{array}$ & Reporte de caso & Cumple reporte JBI \\
\hline $\begin{array}{l}\text { El Dib R, Gomaa H, Carvalho RP, Camargo SE, } \\
\text { Bazan R, Barretti P, et al. } \\
\text { Enzyme replacement therapy for Anderson-Fabry } \\
\text { disease }\end{array}$ & Revisión sistemática & Alta \\
\hline $\begin{array}{l}\text { Fall B, Scott CR, Mauer M, Shankland S, Pippin J, } \\
\text { Jefferson JA, et al. } \\
\text { Urinary Podocyte Loss Is Increased in Patients with } \\
\text { Fabry Disease and Correlates with Clinical Severity } \\
\text { of Fabry Nephropathy. }\end{array}$ & $\begin{array}{c}\text { Cohorte de pacientes } \\
\text { (serie de casos) }\end{array}$ & No cumple reporte JBI \\
\hline $\begin{array}{l}\text { Gal A, Hughes DA, Winchester B. } \\
\text { Toward a consensus in the laboratory diagnostics of } \\
\text { Fabry disease - recommendations of a European } \\
\text { expert group. }\end{array}$ & Recomendaciones & N/A \\
\hline $\begin{array}{l}\text { García-Trabanino R, Badilla-Porras R, Carazo K, } \\
\text { Courville K, de Luna E, Lemus P, et al. } \\
\text { Consenso del Grupo Centroamericano y del Caribe } \\
\text { para el Estudio y Tratamiento de la Enfermedad de } \\
\text { Fabry. }\end{array}$ & $\begin{array}{l}\text { Consenso informal } \\
\text { de expertos }\end{array}$ & $\mathrm{N} / \mathrm{A}$ \\
\hline $\begin{array}{l}\text { Germain DP, ElliottPM, Falissard B, Fomin VV, } \\
\text { Hilz MJ, Jovanovic A, et al. } \\
\text { The effect of enzyme replacement therapy on clinical } \\
\text { outcomes in male patients with Fabry disease: A } \\
\text { systematic literature review by a European panel of } \\
\text { experts. }\end{array}$ & Revisión sistemática & $\begin{array}{l}\text { La metodología no } \\
\text { estuvo disponible para } \\
\text { ser evaluada. }\end{array}$ \\
\hline
\end{tabular}




\begin{tabular}{|c|c|c|}
\hline Documento & Tipo de documento & $\begin{array}{l}\text { Calidad de evidencia - } \\
\text { Riesgo de sesgo }\end{array}$ \\
\hline $\begin{array}{l}\text { Germain DP, Hughes DA, Nicholls K, Bichet DG, } \\
\text { Giugliani R, Wilcox WR, et al. } \\
\text { Treatment of Fabry's Disease with the Pharmacologic } \\
\text { Chaperone Migalastat. }\end{array}$ & Ensayo clínico & $\begin{array}{l}\text { Alto riesgo de sesgo: } \\
\text { no es clara la generación de } \\
\text { aleatorización, tampoco } \\
\text { el cegamiento de quién } \\
\text { administró la intervención y de } \\
\text { quién realiza el análisis. } \\
\text { El análisis de datos incompletos } \\
\text { no está claramente definido. }\end{array}$ \\
\hline $\begin{array}{l}\text { Germain DP. } \\
\text { Fabry disease. }\end{array}$ & Revisión narrativa & $\mathrm{N} / \mathrm{A}$ \\
\hline $\begin{array}{l}\text { Hopkin RJ, Cabrera G, Charrow J, Lemay R, Martins AM, } \\
\text { Mauer M, et al. Risk factors for severe clinical events in } \\
\text { male and female patients with Fabry disease treated with } \\
\text { agalsidase beta enzyme replacement therapy: Data from } \\
\text { the Fabry Registry. }\end{array}$ & Cohorte & Cumple reporte JBI \\
\hline $\begin{array}{l}\text { Hopkin RJ, Cabrera G, Charrow J, Lemay R, Martins AM, } \\
\text { Mauer M, et al. } \\
\text { Risk factors for severe clinical events in male and female } \\
\text { patients with Fabry disease treated with agalsidase beta } \\
\text { enzyme replacement therapy: Data from the Fabry Registry. }\end{array}$ & Registro de pacientes & $\mathrm{N} / \mathrm{A}$ \\
\hline $\begin{array}{l}\text { Hughes DA, Nicholls K, Shankar SP, Sunder-Plassmann G, } \\
\text { Koeller D, Nedd K, et al. } \\
\text { Oral pharmacological chaperone migalastat compared with } \\
\text { enzyme replacement therapy in Fabry disease: } 18 \text { - month } \\
\text { results from the randomised phase III ATTRACT study. }\end{array}$ & Ensayo clínico & $\begin{array}{l}\text { Alto riesgo de sesgo, } \\
\text { no es claro el cegamiento de } \\
\text { quién administró la intervención } \\
\text { y de quién realiza el análisis. } \\
\text { El análisis de datos } \\
\text { incompletos no está claramente } \\
\text { definido. }\end{array}$ \\
\hline $\begin{array}{l}\text { İnan R, Meşe M, Bicik Z. } \\
\text { Multidisciplinary approach to Fabry disease: from the } \\
\text { eye of a neurologist. }\end{array}$ & Tamizaje familiar & $\mathrm{N} / \mathrm{A}$ \\
\hline $\begin{array}{l}\text { Instituto Nacional de Salud (INS). } \\
\text { Boletín Epidemiológico semanal. Semana epidemiológica } 07 \\
14 \text { al } 20 \text { de febrero de } 2021 .\end{array}$ & Boletín & $\mathrm{N} / \mathrm{A}$ \\
\hline $\begin{array}{l}\text { Iwafuchi Y, Maruyama H, Morioka T, Noda S, Nagata H, } \\
\text { Oyama Y, et al. } \\
\text { Enzyme replacement therapy in a patient of heterozygous } \\
\text { Fabry disease: clinical and pathological evaluations by } \\
\text { repeat kidney biopsy and a successful pregnancy. }\end{array}$ & Reporte de caso & Cumple reporte JBI \\
\hline $\begin{array}{l}\text { Jaurretche S, Antongiovanni N, Perretta F. } \\
\text { Fabry nephropathy. Role of nephrologist and clinical } \\
\text { variables associated with the diagnosis. }\end{array}$ & Corte transversal & Cumple reporte JBI \\
\hline
\end{tabular}




\begin{tabular}{|c|c|c|}
\hline Documento & Tipo de documento & $\begin{array}{c}\text { Calidad de evidencia } \\
\text { Riesgo de sesgo }\end{array}$ \\
\hline $\begin{array}{l}\text { Jaurretche S, Perez GR, Venera G. } \\
\text { High Lyso-Gb3 Plasma Levels Associated with Decreased } \\
\text { miR-29 and miR- } 200 \text { Urinary Excretion in Young } \\
\text { Non-Albuminuric Male Patient with Classic Fabry Disease. }\end{array}$ & Reporte de caso & Cumple reporte JBI \\
\hline $\begin{array}{l}\text { Jaurretche SP, Antongiovanni N, Perretta F. } \\
\text { Direct correlation between age at diagnosis and severity } \\
\text { of nephropathy in fabry disease patients. }\end{array}$ & $\begin{array}{l}\text { Corte transversal } \\
\text { analítico }\end{array}$ & $\begin{array}{l}\text { No cumple reporte } \\
\text { en JBI. Análisis } \\
\text { descriptivo no analítico. }\end{array}$ \\
\hline $\begin{array}{l}\text { Kaminsky P, Noel E, Jaussaud R, Leguy-Seguin V, } \\
\text { Hachulla E, Zenone T, et al. } \\
\text { Multidimensional analysis of clinical symptoms in patients } \\
\text { with Fabry's disease. }\end{array}$ & $\begin{array}{l}\text { Cohorte de pacientes } \\
\text { (serie de casos) }\end{array}$ & Cumple reporte JBI \\
\hline $\begin{array}{l}\text { Krämer J, Lenders M, Canaan-Kühl S, Nordbeck P, } \\
\text { Üçeyler N, Blaschke D, et al. } \\
\text { Fabry disease under enzyme replacement therapy-new } \\
\text { insights in efficacy of different dosages. }\end{array}$ & Cohorte & Cumple reporte JBI \\
\hline $\begin{array}{l}\text { Langeveld M, Hollak CE, Veen S Van Der, Eskes E. } \\
\text { Protocol Diagnosis, evaluation and treatment of Fabry } \\
\text { disease in the Netherlands. }\end{array}$ & Protocolo & N/A \\
\hline $\begin{array}{l}\text { Lenders M, Brand E. } \\
\text { Effects of Enzyme Replacement Therapy and Antidrug } \\
\text { Antibodies in Patients with Fabry Disease. }\end{array}$ & Revisión narrativa & N/A \\
\hline $\begin{array}{l}\text { Lenders M, Canaan- Kühl S, Krämer J, Duning T, } \\
\text { Reiermann S, Sommer C, et al. } \\
\text { Patients with Fabry Disease after Enzyme Replacement } \\
\text { Therapy Dose Reduction and Switch-2-Year Follow-Up. }\end{array}$ & Cohorte & $\begin{array}{c}\text { No se describe } \\
\text { ninguna metodología. }\end{array}$ \\
\hline $\begin{array}{l}\text { Lenders M, Neußer LP, Rudnicki M, Nordbeck P, } \\
\text { Canaan-Kühl S, Nowak A, et al. } \\
\text { Dose-Dependent Effect of Enzyme Replacement Therapy } \\
\text { on Neutralizing Antidrug Antibody Titers and Clinical } \\
\text { Outcome in Patients with Fabry Disease. }\end{array}$ & $\begin{array}{c}\text { Cohorte de pacientes } \\
\text { (serie de casos) }\end{array}$ & Cumple reporte JBI \\
\hline $\begin{array}{l}\text { Lenders M, Neußer LP, Rudnicki M, Nordbeck P, } \\
\text { Canaan-Kühl S, Nowak A, et al. } \\
\text { Dose-Dependent Effect of Enzyme Replacement Therapy } \\
\text { on Neutralizing Antidrug Antibody Titers and Clinical } \\
\text { Outcome in Patients with Fabry Disease. }\end{array}$ & $\begin{array}{c}\text { Análisis de datos } \\
\text { biorrepositorio }\end{array}$ & N/A \\
\hline
\end{tabular}




\begin{tabular}{|c|c|c|}
\hline Documento & Tipo de documento & $\begin{array}{l}\text { Calidad de evidencia - } \\
\text { Riesgo de sesgo }\end{array}$ \\
\hline $\begin{array}{l}\text { Lepedda AJ, Fancellu L, Zinellu E, De Muro P, Nieddu G, } \\
\text { Deiana GA, et al. } \\
\text { Urine bikunin as a marker of renal impairment in Fabry's } \\
\text { disease. }\end{array}$ & $\begin{array}{c}\text { Reporte de banco de } \\
\text { muestras }\end{array}$ & $\mathrm{N} / \mathrm{A}$ \\
\hline $\begin{array}{l}\text { Lin HY, Huang YH, Liao HC, Liu HC, Hsu TR, Shen CI, et al. } \\
\text { Clinical observations on enzyme replacement therapy in } \\
\text { patients with Fabry disease and the switch from agalsidase } \\
\text { beta to agalsidase alfa. }\end{array}$ & Serie de casos & Cumple reporte JBI \\
\hline $\begin{array}{l}\text { Langeveld M, Hollak CE, Klein S, van Loon S, } \\
\text { van der Veen M, et al. Protocol Diagnosis, evaluation and } \\
\text { treatment of Fabry disease in the Netherlands. }\end{array}$ & Protocolo & $\mathrm{N} / \mathrm{A}$ \\
\hline $\begin{array}{l}\text { Madsen CV, Granqvist H, Petersen JH, Rasmussen } \AA \mathrm{K} \text {, } \\
\text { Lund AM, Oturai P, et al. } \\
\text { Age-related renal function decline in Fabry disease } \\
\text { patients on enzyme replacement therapy: a longitudinal } \\
\text { cohort study. }\end{array}$ & $\begin{array}{c}\text { Cohorte de pacientes } \\
\text { (serie de casos) }\end{array}$ & Cumple reporte JBI \\
\hline $\begin{array}{l}\text { Martins AM, D’Almeida V, Kyosen SO, Takata ET, } \\
\text { Delgado AG, Gonçalves AM, et al. } \\
\text { Guidelines to diagnosis and monitoring of } \\
\text { Fabry disease and review of treatment experiences. }\end{array}$ & Recomendaciones & $\mathrm{N} / \mathrm{A}$ \\
\hline $\begin{array}{l}\text { Mauer M, Glynn E, Svarstad E, Tøndel C, Gubler M-C, } \\
\text { West M, et al. } \\
\text { Mosaicism of podocyte involvement is related to } \\
\text { podocyte injury in females with Fabry disease. }\end{array}$ & Reporte de biopsias & $\mathrm{N} / \mathrm{A}$ \\
\hline $\begin{array}{l}\text { Mignani R, Pieroni M, Pisani A, Spada M, Battaglia Y, } \\
\text { Verrecchia E, et al. New insights from the application } \\
\text { of the FAbry STabilization indEX in a large population } \\
\text { of Fabry cases. }\end{array}$ & Prueba diagnóstica & $\begin{array}{l}\text { Probabilidad alta de sesgo } \\
\text { por considerar juicio clínico } \\
\text { como estándar de oro, con expertos } \\
\text { clínicos de diferentes en centros de } \\
\text { inclusión, selección de individuos con } \\
\text { registros completos de evaluación } \\
\text { multidisciplinaria anual. No es clara } \\
\text { la inclusión consecutiva o aleatoria de } \\
\text { los pacientes. }\end{array}$ \\
\hline $\begin{array}{l}\text { Ministerio de Salud y Protección Social de Colombia } \\
\text { (MinSalud). } \\
\text { Colombia asume el reto de la atención integral para } \\
\text { enfermedades huérfanas. }\end{array}$ & Comunicación & $\mathrm{N} / \mathrm{A}$ \\
\hline $\begin{array}{l}\text { Müntze J, Gensler D, Maniuc O, Liu D, Cairns T, } \\
\text { Oder D, et al. } \\
\text { Oral Chaperone Therapy Migalastat for Treating } \\
\text { Fabry Disease: Enzymatic Response and Serum } \\
\text { Biomarker Changes After } 1 \text { Year. }\end{array}$ & $\begin{array}{l}\text { Cohorte de pacientes } \\
\text { (serie de casos) }\end{array}$ & No cumple reporte JBI \\
\hline
\end{tabular}




\begin{tabular}{|c|c|c|}
\hline Documento & Tipo de documento & $\begin{array}{l}\text { Calidad de evidencia - } \\
\text { Riesgo de sesgo }\end{array}$ \\
\hline $\begin{array}{l}\text { Najafian B, Tøndel C, Svarstad E, Gubler MC, } \\
\text { Oliveira JP, Mauer M. } \\
\text { Accumulation of Globotriaosylcerami de in Podocytes } \\
\text { in Fabry Nephropathy Is Associated with Progressive } \\
\text { Podocyte Loss. }\end{array}$ & $\begin{array}{l}\text { No está claramente } \\
\text { definido }\end{array}$ & N/A \\
\hline $\begin{array}{l}\text { Najafian B, Tøndel C, Svarstad E, Sokolovkiy A, Smith K, } \\
\text { Mauer M. } \\
\text { One Year of Enzyme Replacement Therapy Reduces } \\
\text { Globotriaosylcerami de Inclusions in Podocytes in Male } \\
\text { Adult Patients with Fabry Disease. Orphannet. The portal } \\
\text { for rare diseases and orphan drugs. }\end{array}$ & Serie de casos & Cumple reporte JBI \\
\hline $\begin{array}{l}\text { Ortiz A, Abiose A, Bichet DG, Cabrera G, Charrow J, } \\
\text { Germain DP, et al. } \\
\text { Time to treatment benefit for adult patients with Fabry } \\
\text { disease receiving agalsidase } \beta \text { : data from the Fabry } \\
\text { Registry. }\end{array}$ & Cohorte & Cumple reporte JBI \\
\hline $\begin{array}{l}\text { Ortiz A, Germain DP, Desnick RJ, Politei J, Mauer M, } \\
\text { Burlina A, et al. } \\
\text { Fabry disease revisited: Management and treatment } \\
\text { recommendations for adult patients. }\end{array}$ & Recomendaciones & N/A \\
\hline $\begin{array}{l}\text { Ortiz A, Kanters S, Hamed A, DasMahapatra P, Poggio E, } \\
\text { Maski M, et al. } \\
\text { Agalsidase beta treatment slows estimated glomerular } \\
\text { filtration rate loss in classic Fabry disease patients: results } \\
\text { from an individual patient data meta-analysis. }\end{array}$ & $\begin{array}{l}\text { Metaanálisis de datos } \\
\text { individuales }\end{array}$ & N/A \\
\hline $\begin{array}{l}\text { Parini R, Pintos- Morell G, Hennermann JB, Hsu TR, } \\
\text { Karabul N, Kalampoki V, et al. } \\
\text { Analysis of Renal and Cardiac Outcomes in Male } \\
\text { Participants in the Fabry Outcome Survey Starting Agalsidase } \\
\text { Alfa Enzyme Replacement Therapy Before and After } 18 \\
\text { Years of Age. }\end{array}$ & Cohorte & No cumple \\
\hline $\begin{array}{l}\text { Passaglia B, Demarchi R, Kirsztajn GM. } \\
\text { Fabry disease: genetics, pathology, and treatment. }\end{array}$ & Revisión narrativa & $\mathrm{N} / \mathrm{A}$ \\
\hline $\begin{array}{l}\text { Pereira EM, Silva AS, Labilloy A, Monte-Neto JT, Monte SJ. } \\
\text { Podocyturia in Fabry disease. }\end{array}$ & Serie de casos & Cumple reporte JBI \\
\hline $\begin{array}{l}\text { Politei J, Aiziczon D, Aguilar MA, Alonso S, Amoreo O, } \\
\text { Andrade LA, et al. } \\
\text { Recomendaciones para el diagnóstico, tratamiento y } \\
\text { seguimiento de la enfermedad de Fabry en Argentina. }\end{array}$ & Recomendaciones & N/A \\
\hline
\end{tabular}




\begin{tabular}{|c|c|c|}
\hline Documento & Tipo de documento & $\begin{array}{l}\text { Calidad de evidencia - } \\
\text { Riesgo de sesgo }\end{array}$ \\
\hline $\begin{array}{l}\text { Riccio E, Sabbatini M, Bruzzese D, Annicchiarico-Petruzzelli L, } \\
\text { Pellegrino A, Spinelli L, et al. } \\
\text { Glomerular Hyperfiltration: An Early Marker of Nephropathy in } \\
\text { Fabry Disease. }\end{array}$ & $\begin{array}{l}\text { Cohorte de pacientes } \\
\text { (serie de casos) }\end{array}$ & Cumple reporte JBI \\
\hline $\begin{array}{l}\text { Riccio E, Sabbatini M, Capuano I, Pisani A. } \\
\text { Early Biomarkers of Fabry Nephropathy: A Review of the Literature. }\end{array}$ & Revisión narrativa & $\mathrm{N} / \mathrm{A}$ \\
\hline $\begin{array}{l}\text { Riccio E, Zanfardino M, Ferreri L, Santoro C, Cocozza S, } \\
\text { Capuano I, et al. } \\
\text { Switch from enzyme replacement therapy to oral chaperone } \\
\text { migalastat for treating fabry disease: real-life data. }\end{array}$ & Serie de casos & Cumple reporte JBI \\
\hline $\begin{array}{l}\text { Ries M, Bove-Bettis KE, Choyke P, Kopp JB, Austin HA, } \\
\text { Brady RO, et al. } \\
\text { Parapelvic kidney cysts: A distinguishing feature with high } \\
\text { prevalence in Fabry disease. }\end{array}$ & $\begin{array}{l}\text { Cohorte de pacientes } \\
\text { (serie de casos) }\end{array}$ & N/A \\
\hline $\begin{array}{l}\text { Ripeau D, Amartino H, Cedrolla M, Urtiaga L, Urdaneta B, } \\
\text { Cano M, et al. } \\
\text { Switch from agalsidase beta to agalsidase alfa in the enzyme } \\
\text { replacement therapy of patients with fabry disease inlatin } \\
\text { America. }\end{array}$ & $\begin{array}{l}\text { Cohorte de pacientes } \\
\text { (serie de casos) }\end{array}$ & Cumple reporte JBI \\
\hline $\begin{array}{l}\text { Roggero L, Auricchio S, Pieruzzi F. } \\
\text { La terapia enzimatica sostitutiva nella malattia di Fabry. }\end{array}$ & Revisión narrativa & $\mathrm{N} / \mathrm{A}$ \\
\hline $\begin{array}{l}\text { Rozenfeld P, Feriozzi S. } \\
\text { Contribution of inflammatory pathways to Fabry disease } \\
\text { pathogenesis. }\end{array}$ & Revisión narrativa & $\mathrm{N} / \mathrm{A}$ \\
\hline $\begin{array}{l}\text { Rozenfeld PA, de Los Angeles-Bolla M, Quieto P, Pisani A, } \\
\text { Feriozzi S, Neuman P, et al. } \\
\text { Pathogenesis of Fabry nephropathy: The pathways leading } \\
\text { to fibrosis. }\end{array}$ & Reporte de biopsias & $\mathrm{N} / \mathrm{A}$ \\
\hline $\begin{array}{l}\text { Sanchez-Niño MD, Perez-Gomez MV, Valiño-Rivas L, } \\
\text { Torra R, Ortiz A. } \\
\text { Podocyturia: why it may have added value in rare diseases. }\end{array}$ & Editorial & $\mathrm{N} / \mathrm{A}$ \\
\hline $\begin{array}{l}\text { Sirrs S, Bichet D, Iwanochko M, Khan A, Moore D, West M. } \\
\text { Canadian Fabry Disease Treatment Guidelines } 2018 .\end{array}$ & GPC & $\begin{array}{l}\text { Agree II: Criterio 3, } \\
\text { rigor metodológico: } 38 \% \\
\text { Criterio 6, independencia } \\
\text { editorial: } 58 \% \text { Puntaje } \\
\text { global: } 2 / 7\end{array}$ \\
\hline $\begin{array}{l}\text { Sasa H, Nagao M, Kino K. } \\
\text { Safety and effectiveness of enzyme replacement therapy } \\
\text { with agalsidase alfa in patients with Fabry disease: Post- } \\
\text { marketing surveillance in Japan. }\end{array}$ & $\begin{array}{l}\text { Cohorte de pacientes } \\
\text { (serie de casos) }\end{array}$ & Cumple reporte JBI \\
\hline $\begin{array}{l}\text { Schiffmann R. } \\
\text { Fabry disease. }\end{array}$ & Revisión de tema & $\mathrm{N} / \mathrm{A}$ \\
\hline
\end{tabular}




\begin{tabular}{|c|c|c|}
\hline Documento & Tipo de documento & $\begin{array}{c}\text { Calidad de evidencia - } \\
\text { Riesgo de sesgo }\end{array}$ \\
\hline $\begin{array}{l}\text { Sirrs SM, Bichet DG, Casey R, Clarke JTR, Lemoine K, } \\
\text { Doucette S, et al. } \\
\text { Outcomes of patients treated through the Canadian } \\
\text { Fabry disease initiative. }\end{array}$ & Cohorte de pacientes & $\mathrm{N} / \mathrm{A}$ \\
\hline $\begin{array}{l}\text { Skrunes R, Svarstad E, Kampevold Larsen K, Leh S, } \\
\text { Tøndel C. Reaccumulation of globotriaosylcerami de } \\
\text { in podocytes after agalsidase dose reduction in young } \\
\text { Fabry patients. }\end{array}$ & $\begin{array}{l}\text { Cohorte de pacientes } \\
\text { (serie de casos) }\end{array}$ & Cumple reporte JBI \\
\hline $\begin{array}{l}\text { Skrunes R, Svarstad E, Kampevold Larsen K, Leh S, } \\
\text { Tøndel C. } \\
\text { Reaccumulation of globotriaosylcerami de in podocytes } \\
\text { after agalsidase dose reduction in young Fabry patients. }\end{array}$ & Serie de casos & Cumple reporte JBI \\
\hline $\begin{array}{l}\text { Skrunes R, Tøndel C, Leh S, Larsen KK, Houge G, } \\
\text { Davidsen ES, et al. } \\
\text { Long-Term Dose-Dependent Agalsidase Effects on Kidney } \\
\text { Histology in Fabry Disease. }\end{array}$ & Serie de casos & Cumple reporte JBI \\
\hline $\begin{array}{l}\text { Spada M, Pagliardini S, Yasuda M, Tukel T, Thiagarajan G, } \\
\text { Sakuraba H, et al. } \\
\text { High incidence of later-onset fabry disease revealed by } \\
\text { newborn screening. }\end{array}$ & $\begin{array}{c}\text { Estudio de tamización } \\
\text { poblacional }\end{array}$ & $\mathrm{N} / \mathrm{A}$ \\
\hline $\begin{array}{l}\text { Terryn W, Cochat P, Froissart R, Ortiz A, Pirson Y, } \\
\text { Poppe B, et al. } \\
\text { Fabry nephropathy: indications for screening and guidance } \\
\text { for diagnosis and treatment by the European Renal Best } \\
\text { Practice. }\end{array}$ & Recomendaciones & N/A \\
\hline $\begin{array}{l}\text { Terryn W, Cochat P, Froissart R, Ortiz A, Pirson Y, } \\
\text { Poppe B, et al. } \\
\text { Fabry nephropathy: indications for screening and } \\
\text { guidance for diagnosis and treatment by the European } \\
\text { Renal Best Practice. }\end{array}$ & Guía & $\begin{array}{l}\text { Agree II: Criterio 3, } \\
\text { rigor metodológico: } 33 \% \\
\text { Criterio 6, independencia } \\
\text { editorial: } 67 \% \text { Puntaje } \\
\text { global: } 2 / 7\end{array}$ \\
\hline $\begin{array}{l}\text { Trimarchi H, Canzonieri R, Schiel A, Politei J, } \\
\text { Costales-Collaguazo C, Stern A, et al. } \\
\text { Expression of uPAR in Urinary Podocytes of Patients with } \\
\text { Fabry Disease. }\end{array}$ & $\begin{array}{l}\text { Corte transversal } \\
\text { analítico }\end{array}$ & Cumple reporte JBI \\
\hline $\begin{array}{l}\text { Trimarchi H, Forrester M, Lombi F, Pomeranz V, Raña MS, } \\
\text { Karl A, et al. } \\
\text { Amiloride as an Alternate Adjuvant Antiproteinuric Agent } \\
\text { in Fabry Disease: The Potential Roles of Plasmin and uPAR. }\end{array}$ & Reporte de caso & No cumple reporte JBI \\
\hline
\end{tabular}




\begin{tabular}{|c|c|c|}
\hline Documento & Tipo de documento & $\begin{array}{l}\text { Calidad de evidencia - } \\
\text { Riesgo de sesgo }\end{array}$ \\
\hline $\begin{array}{l}\text { Tsuboi K, Yamamoto } \mathrm{H} \text {. } \\
\text { Clinical observation of patients with Fabry disease } \\
\text { after switching from agalsidase beta (Fabrazyme) to } \\
\text { agalsidase alfa (Replagal). }\end{array}$ & Serie de casos & Cumple reporte JBI \\
\hline $\begin{array}{l}\text { Turkmen K, Baloglu } \\
\text { I. Fabry disease: where are we now? }\end{array}$ & Revisión narrativa & $\mathrm{N} / \mathrm{A}$ \\
\hline $\begin{array}{l}\text { Turkmen K, Guclu A, Sahin G, Kocyigit I, Demirtas L, } \\
\text { Erdur FM, et al. } \\
\text { The Prevalence of Fabry Disease in Patients with Chronic } \\
\text { Kidney Disease in Turkey: The TURKFAB Study. }\end{array}$ & Corte transversal & Cumple reporte JBI \\
\hline $\begin{array}{l}\text { Valbuena C, Carvalho E, Bustorff M, Ganhão M, } \\
\text { Relvas S, Nogueira R, et al. } \\
\text { Kidney biopsy findings in heterozygous Fabry disease } \\
\text { females with early nephropathy. }\end{array}$ & $\begin{array}{l}\text { Reporte de banco de } \\
\text { muestras }\end{array}$ & $\mathrm{N} / \mathrm{A}$ \\
\hline $\begin{array}{l}\text { van der Tol L, Svarstad E, Ortiz A, Tøndel C, Oliveira JP, } \\
\text { Vogt L, et al. } \\
\text { Chronic kidney disease and an uncertain diagnosis of Fabry } \\
\text { disease: Approach to a correct diagnosis. }\end{array}$ & Consenso de expertos & $\mathrm{N} / \mathrm{A}$ \\
\hline $\begin{array}{l}\text { Vujkovac B. } \\
\text { Fabry disease: diagnostic methods in nephrology practice. }\end{array}$ & Revisión narrativa & $\mathrm{N} / \mathrm{A}$ \\
\hline $\begin{array}{l}\text { Waldek S, Feriozzi } \\
\text { S. Fabry nephropathy: a review - how can we optimize the } \\
\text { management of Fabry nephropathy? }\end{array}$ & Revisión narrativa & $\mathrm{N} / \mathrm{A}$ \\
\hline $\begin{array}{l}\text { Wanner C, Arad M, Baron R, Burlina A, Elliott PM, Feldt- } \\
\text { Rasmussen U, et al. } \\
\text { European expert consensus statement on therapeutic goals } \\
\text { in Fabry disease. }\end{array}$ & $\begin{array}{l}\text { Consenso informal } \\
\text { de expertos }\end{array}$ & $\mathrm{N} / \mathrm{A}$ \\
\hline $\begin{array}{l}\text { Warnock DG, Daina E, Remuzzi G, West M. } \\
\text { Enzyme replacement therapy and Fabry nephropathy. }\end{array}$ & Revisión narrativa & $\mathrm{N} / \mathrm{A}$ \\
\hline $\begin{array}{l}\text { Weidemann F, Niemann M, Störk S, Breunig F, Beer M, } \\
\text { Sommer C, et al. } \\
\text { Long-term outcome of enzyme- replacement therapy in } \\
\text { advanced Fabry disease: evidence for disease progression } \\
\text { towards serious complications. }\end{array}$ & Cohorte & No cumple \\
\hline $\begin{array}{l}\text { Yeniçerioğlu Y, Akdam H, Dursun B, Alp A, Eyiler FS, } \\
\text { Akın D, et al. } \\
\text { Screening Fabry's disease in chronic kidney disease } \\
\text { patients not on dialysis: A multicenter study. }\end{array}$ & $\begin{array}{l}\text { Corte transversal } \\
\text { analítico }\end{array}$ & No cumple reporte en JBI \\
\hline $\begin{array}{l}\text { Zhang R, Chen Z, Lang Y, Shao S, Cai Y, You Q, et al. } \\
\text { Sudden onset of nephrotic syndrome in an asymptomatic } \\
\text { Fabry patient: a case report. }\end{array}$ & Reporte de caso & Cumple reporte JBI \\
\hline
\end{tabular}




\section{Anexo D. Resultados de la votación de la consulta preconsenso}

\begin{tabular}{|c|c|}
\hline Recomendación & $\begin{array}{l}\text { Porcentaje } \\
\text { de } \\
\text { acuerdo }\end{array}$ \\
\hline $\begin{array}{l}\text { ¿Qué es la enfermedad de Fabry? [La enfermedad de Fabry es una } \\
\text { condición de compromiso multisistémico, huérfana, hereditaria y ligada al } \\
\text { cromosoma X, que pertenece al grupo de las enfermedades de depósito } \\
\text { lisosomal]. }\end{array}$ & $100 \%$ \\
\hline $\begin{array}{l}\text { ¿Cuáles son las manifestaciones clínicas generales? [Las manifestaciones } \\
\text { clínicas de la enfermedad de Fabry se asocian con el fenotipo, el cual } \\
\text { puede ser clásico (inicio temprano) o tardío. El fenotipo clásico se } \\
\text { caracteriza por inicio temprano de signos y síntomas que incluyen la } \\
\text { acroparestesia, hipo o anhidrosis, trastornos gastrointestinales, intolerancia } \\
\text { al ejercicio, fiebre, angioqueratoma, dolor neuropático, cornea verticillata, } \\
\text { tinnitus y vértigo, entre otros. Durante la historia natural de la enfermedad } \\
\text { los pacientes evolucionan a daño renal, cardiaco y cerebrovascular]. }\end{array}$ & $100 \%$ \\
\hline $\begin{array}{l}\text { ¿Cuáles son las manifestaciones clínicas generales? [El fenotipo tardío se } \\
\text { presenta en la adultez con predominio de afección cardiaca, y grados } \\
\text { variables de compromiso renal y cerebrovascular]. }\end{array}$ & $100 \%$ \\
\hline $\begin{array}{l}\text { ¿Cuáles son las manifestaciones clínicas generales? [La edad de inicio de } \\
\text { manifestaciones de la enfermedad en el fenotipo clásico ocure en la niñez } \\
\text { a partir de los } 3 \text { años y para el fenotipo tardío después de los } 30 \text { años]. }\end{array}$ & $100 \%$ \\
\hline $\begin{array}{l}\text { ¿Cómo se manifiesta la enfermedad a nivel renal? [Las manifestaciones } \\
\text { renales de la enfermedad de Fabry se caracterizan por hiperfiltración con o } \\
\text { sin albuminuria, progresión a proteinuria manifiesta y disminución } \\
\text { progresiva de la TFG. Puede observarse también nicturia como } \\
\text { consecuencia de alteraciones en capacidad de concentración urinaria]. }\end{array}$ & $100 \%$ \\
\hline $\begin{array}{l}\text { ¿Cómo se manifiesta la enfermedad a nivel renal? [El compromiso renal } \\
\text { en Fabry clásico se presenta antes de los } 25 \text { años en hombres y } 35 \text { años en } \\
\text { mujeres y en variantes tardías puede aparecer después de estas edades]. }\end{array}$ & $100 \%$ \\
\hline $\begin{array}{l}\text { ¿Cuál es el perfil epidemiológico de la enfermedad de Fabry? [ La } \\
\text { enfermedad de Fabry es una enfermedad de baja frecuencia y no se conoce }\end{array}$ & $100 \%$ \\
\hline
\end{tabular}




\begin{tabular}{|c|c|}
\hline $\begin{array}{l}\text { hasta ahora información exacta de la prevalencia de la enfemedad en } \\
\text { Colombia, por lo que son necesarios estudios que permitan establecerla]. }\end{array}$ & \\
\hline $\begin{array}{l}\text { ¿Cómo se diagnóstica la enfermedad de Fabry? [Se recomienda realizar } \\
\text { una evaluación integral del paciente con sospecha de enfermedad de Fabry } \\
\text { clásico (cómea verticillata, acroparestesias y dolor neuropático), revisión } \\
\text { retrospectiva de sistemas y realizar tempranamente pruebas diagnósticas]. }\end{array}$ & $100 \%$ \\
\hline $\begin{array}{l}\text { ¿Cómo se diagnóstica la enfermedad de Fabry? [Se recomienda considerar } \\
\text { los criterios clínicos, bioquímicos, moleculares e histopatológicos para el } \\
\text { diagnóstico de la enfermedad de Fabry]. }\end{array}$ & $100 \%$ \\
\hline $\begin{array}{l}\text { ¿Cómo se diagnóstica la enfermedad de Fabry? [En el paciente con } \\
\text { alteración renal y sospecha de enfermedad de Fabry se sugiere considerar } \\
\text { la biopsia renal como una prueba diagnóstica complementaria]. }\end{array}$ & $80 \%$ \\
\hline $\begin{array}{l}\text { ¿Cómo se diagnóstica la enfermedad de Fabry? [Se recomienda realizar } \\
\text { diagnóstico genético de la enfermedad de Fabry en mujeres, a partir de la } \\
\text { identificación de la mutación del gen GLA]. }\end{array}$ & $100 \%$ \\
\hline $\begin{array}{l}\text { ¿Cómo se diagnóstica la enfermedad de Fabry? [Se recomienda evaluar la } \\
\text { actividad de la enzima GLA para el diagnóstico de enfermedad de Fabry } \\
\text { en hombres y de manera complementaria realizar estudio genético en } \\
\text { busca de mutación del gen GLA]. }\end{array}$ & $100 \%$ \\
\hline $\begin{array}{l}\text { ¿Cómo se diagnóstica el compromiso renal por Fabry? [Se recomienda } \\
\text { usar la definición y clasificación de ERC propuesta por KDIGO para } \\
\text { describir la afectación renal por enfermedad de Fabry]. }\end{array}$ & $80 \%$ \\
\hline $\begin{array}{l}\text { ¿Cómo se diagnóstica el compromiso renal por Fabry? [Se recomienda } \\
\text { realizar medición de TFG, cociente albuminuria/creatinuria y proteinuria } \\
\text { de } 24 \text { horas como marcadores de compromiso y progresión renal por } \\
\text { enfermedad de Fabry]. }\end{array}$ & $100 \%$ \\
\hline $\begin{array}{l}\text { ¿Cómo se diagnóstica el compromiso renal por Fabry? [Se sugiere realizar } \\
\text { ecografía renal para evaluación estructural inicial]. }\end{array}$ & $80 \%$ \\
\hline $\begin{array}{l}\text { ¿Cómo se diagnóstica el compromiso renal por Fabry? [Se considera que } \\
\text { en el futuro la podocituria podría ser una herramienta de valor para definir } \\
\text { compromiso renal temprano, debe definirse el marcador de podocitos a } \\
\text { usar, ya que en la enfermedad de Fabry se altera la expresión de }\end{array}$ & $100 \%$ \\
\hline
\end{tabular}


podocalixina en relación con la de sinaptopodina].

¿Cuáles son los exámenes de apoyo para un paciente con enfermedad de

Fabry? [Se recomienda realizar evaluación clínica integral al menos una

vez al año en pacientes con sospecha de enfermedad de Fabry, incluyendo

examen físico, evaluación de dolor neuropático, de compromiso

gastrointestinal y de calidad de vida].

$80 \%$

¿Cuáles son los exámenes de apoyo para un paciente con enfermedad de

Fabry? [Se sugiere realizar tamización de enfermedad de Fabry en

pacientes con alteración en la función renal sin causa conocida].

¿Cuáles son los exámenes de apoyo para un paciente con enfermedad de

Fabry? [Se recomienda medición de albuminuria y proteinuria, TFG,

laboratorios clínicos completos, electrocardiograma, ecocardiograma en

adultos con sospecha de enfermedad de Fabry, al menos una vez al año para evaluar compromiso de órganos].

¿Cuáles son los exámenes de apoyo para un paciente con enfermedad de

Fabry? [Se recomienda que la evaluación sea integral y multidisciplinaria, incluyendo especialistas en cardiología, neurología y nefrología].

$100 \%$

Está de acuerdo con las recomendaciones consignadas en la tabla anterior (recomendaciones para la evaluación inicial y seguimiento del paciente con enfermedad de Fabry

Si está en desacuerdo con la tabla anterior, precise su desacuerdo y los motivos brevemente.

¿Cuándo indicar la biopsia renal en paciente con enfermedad de Fabry?

[Se sugiere considerar la biopsia renal con microscopia electrónica en casos de progresión rápida que no se ajuste a la historia natural de la enfermedad, como en casos de pérdida rápida de la función renal o aumento súbito o no esperado de la proteinuria, con el fin de excluir otros diagnósticos como enfermedades glomerulares intercurrentes o nefrotoxicidad por medicamentos, entre otros] $100 \%$ ¿Cuándo indicar la biopsia renal en paciente con enfermedad de Fabry? $\quad 80 \%$ [En caso de variante de significado incierto en las que haya compromiso renal dadas por alteraciones de la TFG o sedimento y cuando la biopsia 


\begin{tabular}{|c|c|}
\hline $\begin{array}{l}\text { ¿Cuáles son los hallazgos histopatológicos en la biopsia renal? [ } \mathrm{La} \\
\text { vacuolización celular en podocitos, mesangio y célula endotelial con } \\
\text { acumulación de glicoesfingolípidos (cuerpos de cebra) es el principal } \\
\text { hallazgo histopatológico temprano sugestivo de enfermedad de Fabry en la } \\
\text { biopsia renal]. }\end{array}$ & $100 \%$ \\
\hline $\begin{array}{l}\text { ¿Cuáles son los hallazgos histopatológicos en la biopsia renal? [Se sugiere } \\
\text { que la presencia de esclerosis glomerular focal, engrosamiento mesangial, } \\
\text { cambios vasculares, atrofia tubular y fibrosis intersticial son signos de } \\
\text { daño renal avanzado en enfemedad de Fabry]. }\end{array}$ & $100 \%$ \\
\hline $\begin{array}{l}\text { ¿Cuáles enfermedades glomerulares y tubulares son diagnóstico } \\
\text { diferencial de la enfermedad de Fabry? [Se sugiere considerar como } \\
\text { diagnóstico diferencial histopatológico de la variante renal de Fabry la } \\
\text { gangliosidosis GM1, la enfermedad de células I, el síndrome de Hurler, la } \\
\text { enfermedad de Niemann-Pick, la enfermedad de Farber y la enfermedad } \\
\text { de Batten]. }\end{array}$ & $80 \%$ \\
\hline $\begin{array}{l}\text { ¿Cuáles enfermedades glomerulares y tubulares son diagnóstico } \\
\text { diferencial de la enfermedad de Fabry? [Debe considerarse descartar } \\
\text { lipidosis renal por cloroquina, hidroxicloroquina, amiodarona, metadona, } \\
\text { levomepromazina, promasina, amitriptilina, clozapina, enitromicina, } \\
\text { fluoxetina, sertralina, entre otros]. }\end{array}$ & $100 \%$ \\
\hline $\begin{array}{l}\text { ¿Cómo evaluar la respuesta al tratamiento de terapias de reemplazo } \\
\text { enzimático? [Se recomienda evaluar la respuesta renal a la TRE con } \\
\text { relación albuminuria:creatinuria y cambios de TFG, estimada con fórmula } \\
\text { CKD-EPI, considerando como valores de referencia los previos al inicio } \\
\text { de la terapia]. }\end{array}$ & $100 \%$ \\
\hline $\begin{array}{l}\text { ¿Cómo evaluar la respuesta al tratamiento de terapias de reemplazo } \\
\text { enzimático? [Considere la realización de biopsia renal según lo indicado } \\
\text { en la pregunta antes descrita]. }\end{array}$ & $60 \%$ \\
\hline $\begin{array}{l}\text { ¿Cuáles son los criterios desde el punto de vista renal para iniciar } \\
\text { tratamiento de reemplazo enzimático? [Se sugiere el inicio de tratamiento } \\
\text { con TRE en pacientes con Fabry diagnosticado, considerando también }\end{array}$ & $80 \%$ \\
\hline
\end{tabular}




\begin{tabular}{|c|c|}
\hline nte : & \\
\hline $\begin{array}{l}\text { ¿Cuáles son los criterios desde el punto de vista renal para iniciar } \\
\text { tratamiento de reemplazo enzimático? [Se recomienda iniciar la TRE ante } \\
\text { la afectación renal por enfermedad de Fabry evidenciada por (i) TFGe } \\
\text { menor a } 90 \mathrm{ml} / \text { min (ajustada a edad) confimmada en dos recolecciones de } \\
\text { orina en mínimo dos meses o (ii) presencia de albuminuria persistente } \\
\text { mayor a } 30 \mathrm{mg} / \mathrm{g} \text { y confirmada con mínimo dos muestras y (iii) en caso de } \\
\text { disponibilidad de biopsia renal, hallazgos de daño como fusión de } \\
\text { procesos podocitarios, inclusiones y acumulo de glicoesfingolípidos en } \\
\text { varios tipos celulares]. }\end{array}$ & $100 \%$ \\
\hline $\begin{array}{l}\text { ¿Cuáles son los criterios desde el punto de vista renal para iniciar } \\
\text { tratamiento de reemplazo enzimático? [Se sugiere considerar iniciar la } \\
\text { TRE en casos de hiperfiltración (TFG > 135ml/min) y ante la disminución } \\
\text { de pendiente de TFGe mayor al } 15 \% \text { respecto a medición inicial, medido } \\
\text { por método isotópico]. }\end{array}$ & $100 \%$ \\
\hline $\begin{array}{l}\text { ¿Cuáles son los criterios desde el punto de vista renal para iniciar } \\
\text { tratamiento de reemplazo enzimático? [Se sugiere considerar la TRE en } \\
\text { pacientes con terapia de soporte renal (TSR) para proteger otros órganos y } \\
\text { prevenir complicaciones, posterior a evaluación clínica y análisis de } \\
\text { potencial beneficio clínico para el paciente]. }\end{array}$ & $80 \%$ \\
\hline $\begin{array}{l}\text { ¿Cuáles son los criterios desde el punto de vista renal para iniciar } \\
\text { tratamiento de reemplazo enzimático? [En caso de Fabry de inicio tardío } \\
\text { se sugiere comprobación clínica, paraclínica (lyso-Gb3) e histológica en } \\
\text { presencia de indicadores de daño renal para excluir otros diagnósticos, } \\
\text { antes de iniciar TRE]. }\end{array}$ & $100 \%$ \\
\hline $\begin{array}{l}\text { ¿Existen otros tratamientos para evitar la progresión renal? [A pesar de } \\
\text { avances en nuevos tratamientos para la enfermedad de Fabry, aún no es } \\
\text { posible recomendar una altemativa específica, diferente a las ya conocidas } \\
\text { como TRE y chaperonas]. }\end{array}$ & $100 \%$ \\
\hline $\begin{array}{l}\text { ¿Existen otros tratamientos para evitar la progresión renal? [En pacientes } \\
\text { con excreción anormal de proteínas en la orina se sugiere el uso de IECAS } \\
\text { o ARA II, como estrategia coadyuvante para disminuir la velocidad de }\end{array}$ & $100 \%$ \\
\hline
\end{tabular}




\begin{tabular}{|c|c|}
\hline progresión del daño renal]. & \\
\hline $\begin{array}{l}\text { ¿Existen otros tratamientos para evitar la progresión renal? [Se } \\
\text { recomienda en todos los pacientes con Fabry adoptar medidas de } \\
\text { nefroprotección demostradas para retrasar progresión de daño renal, } \\
\text { incluyendo actividad física, dieta hiposódica, control de sobrepeso, lípidos } \\
\text { e hiperglicemia, cesar tabaquismo, entre otras]. }\end{array}$ & $100 \%$ \\
\hline $\begin{array}{l}\text { ¿Existen otros tratamientos para evitar la progresión renal? [Se sugiere } \\
\text { educar a los pacientes para evitar la automedicación y el uso inadvertido o } \\
\text { prescrito de medicamentos con potencial de nefrotoxicidad, incluyendo } \\
\text { medios de contraste y antiinflamatorios no esteroideos, entre otros]. }\end{array}$ & $100 \%$ \\
\hline $\begin{array}{l}\text { ¿Cuál es la indicación de chaperonas? [A pesar de que la terapia con } \\
\text { chaperona (migalastat) es prometedora para el manejo de enfermedad de } \\
\text { Fabry, su eficacia aún es controvertida, por lo que se sugiere el uso de } \\
\text { tratamiento oral con chaperonas (migalastat) en pacientes mayores de } 16 \\
\text { años con enfermedad de Fabry con una mutación susceptible confimada y } \\
\text { una TFGe superior a } 30 \mathrm{ml} / \mathrm{min} / 1,73 \mathrm{~m}^{2} \text { ]. }\end{array}$ & $80 \%$ \\
\hline $\begin{array}{l}\text { ¿Existe diferencia entre las terapias de reemplazo enzimático en resultados } \\
\text { renales? [La evidencia disponible no permite establecer una diferencia } \\
\text { consistente entre los dos tratamientos de reemplazo enzimático agalsidasa- } \\
\alpha \text { y agalsidasa- } \beta \text {, sobre desenlaces renales] }\end{array}$ & $60 \%$ \\
\hline $\begin{array}{l}\text { ¿Existe diferencia entre las terapias de reemplazo enzimático en resultados } \\
\text { renales? [Estudios sugieren un beneficio mayor en la mejoría de los } \\
\text { hallazgos histológicos y una disminución de progresión de la pérdida de } \\
\text { TFG en pacientes con tratamiento con agalsidasa- } \beta \text { a dosis a } 1 \mathrm{mg} / \mathrm{kg} / 2 \\
\text { semanas]. }\end{array}$ & $80 \%$ \\
\hline $\begin{array}{l}\text { ¿Cuál es el impacto clínico de los anticuerpos contra la terapia enzimática? } \\
\text { [Se sugiere considerar la medición de anticuerpos en pacientes que a pesar } \\
\text { de tratamiento ininterrumpido presenta evolución tórpida, deterioro de } \\
\text { función renal evidenciada en TFGe o aumento de Lyso-Gb3]. }\end{array}$ & $80 \%$ \\
\hline $\begin{array}{l}\text { ¿Cuál es el impacto clínico de los anticuerpos contra la terapia enzimática? } \\
\text { [Se sugiere medir los títulos de anticuerpos contra la TRE al menos una } \\
\text { vez al año y, en caso de ser positivos, medir también el Lyso-Gb3. En caso }\end{array}$ & $80 \%$ \\
\hline
\end{tabular}




\begin{tabular}{|c|c|}
\hline $\begin{array}{l}\text { de que el paciente esté siendo tratado con agalsidasa- } \alpha \text {, considere cambio a } \\
\text { agalsidasa- } \beta \text { a dosis estándar]. }\end{array}$ & \\
\hline $\begin{array}{l}\text { ¿Cuál es el impacto clínico de los anticuerpos contra la terapia enzimática? } \\
\text { [Se sugiere mantener dosis de agalsidasa- } \beta \text { antes que cambiar o modificar } \\
\text { de TRE, ante la presencia de anticuerpos neutralizantes]. }\end{array}$ & $100 \%$ \\
\hline $\begin{array}{l}\text { ¿Cuándo está indicado el cambio de terapia? [Antes de decidir un cambio } \\
\text { en el tratamiento, se sugiere considerar descartar otros factores que } \\
\text { influyan en los desenlaces tales como adherencia, entrega y aplicación } \\
\text { cumplida de la medicación]. }\end{array}$ & $100 \%$ \\
\hline $\begin{array}{l}\text { ¿Cuándo está indicado el cambio de terapia? [Se sugiere documentar la } \\
\text { elevación de lyso-Gb3 que puede asociarse con presencia de anticuerpos } \\
\text { que interfieran con la efectividad del tratamiento]. }\end{array}$ & $80 \%$ \\
\hline $\begin{array}{l}\text { ¿Cuándo está indicado el cambio de terapia? [En caso de anticuerpos } \\
\text { neutralizantes contra TRE positivos se sugiere considerar cambio de } \\
\text { agalsidasa- } \alpha 0,2 \mathrm{mg} / \mathrm{kg} / 2 \text { semanas a agalsidasa- } \beta \text { dosis de } 1 \mathrm{mg} / \mathrm{kg} / 2 \\
\text { semanas y en caso de encontrarse en esquema de tratamiento con } \\
\text { agalsidasa- } \beta \text { se sugiere mantener la dosis]. }\end{array}$ & $80 \%$ \\
\hline $\begin{array}{l}\text { ¿Cuándo está indicado el cambio de terapia? [En caso de que el paciente } \\
\text { tenga mala evolución clínica o aumento de Lyso-Gb3 en esquema de } \\
\text { agalsidasa- } \alpha \text { o } \beta \text { con dosis de } 0,2 \mathrm{mg} / \mathrm{kg} / 2 \text { semanas, se sugiere cambio a } \\
\text { agalsidasa- } \beta \text { dosis estándar]. }\end{array}$ & $80 \%$ \\
\hline $\begin{array}{l}\text { ¿Cuál es el valor del Lyso-Gb3 en enfermedad de Fabry?, ¿cuál es la } \\
\text { interpretación del Lyso-Gb3 en el diagnóstico y seguimiento de } \\
\text { enfermedad de Fabry? [Se sugiere considerar concentraciones de Lyso- } \\
\text { Gb3 superiores a } 0,5 \text { ng/ml en fenotipo clásico, como niveles altos que } \\
\text { potencialmente favorecen el daño renal en pacientes con enfermedad de } \\
\text { Fabry]. }\end{array}$ & $100 \%$ \\
\hline $\begin{array}{l}\text { ¿Cuál es el valor del Lyso-Gb3 en enfermedad de Fabry?, ¿cuál es la } \\
\text { interpretación del Lyso-Gb3 en el diagnóstico y seguimiento de } \\
\text { enfermedad de Fabry? [En caso de variantes tardías o mujeres, los niveles } \\
\text { de Lyso-Gb3 pueden no estar relacionados directamente con la progresión } \\
\text { de daño de órgano blanco]. }\end{array}$ & $100 \%$ \\
\hline
\end{tabular}




\begin{tabular}{|l|l|}
\hline $\begin{array}{l}\text { ¿Cuál es el valor del Lyso-Gb3 en enfermedad de Fabry?, ¿cuál es la } \\
\text { interpretación del Lyso-Gb3 en el diagnóstico y seguimiento de } \\
\text { enfermedad de Fabry? [Se sugiere considerar el Lyso-Gb3 como } \\
\text { biomarcador de seguimiento en enfermedad de Fabry con fenotipo clásico } \\
\text { al menos dos veces por año, correlacionando su resultado con el cuadro } \\
\text { clínico y la evaluación integral]. }\end{array}$ & \multirow{2}{*}{$100 \%$} \\
\hline $\begin{array}{l}\text { ¿Cuál es el valor del Lyso-Gb3 en enfermedad de Fabry?, ¿cuál es la } \\
\text { interpretación del Lyso-Gb3 en el diagnóstico y seguimiento de } \\
\text { enfermedad de Fabry? [Se sugiere no usar los niveles de Lyso-Gb3 para } \\
\text { evaluar la respuesta a tratamiento con chaperonas (migalastat)]. }\end{array}$ & $60 \%$ \\
\hline
\end{tabular}

Fuente: elaboración propia. 


\section{Resultados de la votación de consenso de expertos (ronda 1)}

\begin{tabular}{|l|l|}
\hline Recomendación & $\begin{array}{l}\text { Porcentaje de } \\
\text { acuerdo }\end{array}$ \\
\hline $\begin{array}{l}\text { Se sugiere considerar la realización de biopsia renal en pacientes con } \\
\text { Fabry con terapia de reemplazo enzimático que presenten una } \\
\text { evolución diferente a la esperada con relación a lo descrito en } \\
\text { pacientes tratados. }\end{array}$ & $100 \%$ \\
\hline $\begin{array}{l}\text { La evidencia disponible no permite establecer una diferencia } \\
\text { consistente entre los dos tratamientos de reemplazo enzimático } \\
\text { agalsidasa- } \alpha \text { y agalsidasa- } \beta \text {, sobre desenlaces renales. }\end{array}$ & $80 \%$ \\
\hline $\begin{array}{l}\text { Se sugiere interpretar con precaución los niveles Lyso-Gb3 en la } \\
\text { evaluación de tratamiento con chaperonas. Deben tenerse en cuenta } \\
\text { la evolución clínica y otros marcadores de deterioro. }\end{array}$ & $100 \%$ \\
\hline
\end{tabular}

